\title{
Citrullinated peptide epitope targets therapeutic nanoparticles to human neutrophils
}

Khatri, Sangita; Hansen, Jonas; Mendes, Ana Carina Loureiro; Chronakis, loannis S.; Hung, Shu-Chen; Mellins, Elizabeth; Astakhova, Kira

Published in:

Bioconjugate Chemistry

Link to article, DOI:

10.1021/acs.bioconjchem.9b00518

Publication date:

2019

Document Version

Peer reviewed version

Link back to DTU Orbit

Citation (APA):

Khatri, S., Hansen, J., Mendes, A. C. L., Chronakis, I. S., Hung, S-C., Mellins, E., \& Astakhova, K. (2019).

Citrullinated peptide epitope targets therapeutic nanoparticles to human neutrophils. Bioconjugate Chemistry, 30(10), 2584-2593. https://doi.org/10.1021/acs.bioconjchem.9b00518

\section{General rights}

Copyright and moral rights for the publications made accessible in the public portal are retained by the authors and/or other copyright owners and it is a condition of accessing publications that users recognise and abide by the legal requirements associated with these rights.

- Users may download and print one copy of any publication from the public portal for the purpose of private study or research.

- You may not further distribute the material or use it for any profit-making activity or commercial gain

- You may freely distribute the URL identifying the publication in the public portal 


\section{Article}

Subscriber access provided by DTU Library

\section{Citrullinated peptide epitope targets therapeutic nanoparticles to human neutrophils}

Sangita Khatri, Jonas Hansen, Ana C. Mendes, loannis S. Chronakis, Shu-Chen Hung, Elizabeth Mellins, and Kira Astakhova

Bioconjugate Chem., Just Accepted Manuscript • DOI: 10.1021/acs.bioconjchem.9b00518 • Publication Date (Web): 16 Sep 2019

Downloaded from pubs.acs.org on September 23, 2019

\section{Just Accepted}

"Just Accepted" manuscripts have been peer-reviewed and accepted for publication. They are posted online prior to technical editing, formatting for publication and author proofing. The American Chemical Society provides "Just Accepted" as a service to the research community to expedite the dissemination of scientific material as soon as possible after acceptance. "Just Accepted" manuscripts appear in full in PDF format accompanied by an HTML abstract. "Just Accepted" manuscripts have been fully peer reviewed, but should not be considered the official version of record. They are citable by the Digital Object Identifier (DOI@). "Just Accepted" is an optional service offered to authors. Therefore, the "Just Accepted" Web site may not include all articles that will be published in the journal. After a manuscript is technically edited and formatted, it will be removed from the "Just Accepted" Web site and published as an ASAP article. Note that technical editing may introduce minor changes to the manuscript text and/or graphics which could affect content, and all legal disclaimers and ethical guidelines that apply to the journal pertain. ACS cannot be held responsible for errors or consequences arising from the use of information contained in these "Just Accepted" manuscripts. 


\title{
Citrullinated peptide epitope targets therapeutic nanoparticles to human neutrophils
}

\author{
Sangita Khatri, ${ }^{1}$ Jonas Hansen,,${ }^{1,2}$ Ana C. Mendes, ${ }^{3}$ Ioannis S. Chronakis, ${ }^{3}$ Shu-Chen Hung, ${ }^{4}$ Elizabeth \\ D. Mellins, ${ }^{4}$ and Kira Astakhova ${ }^{1, *}$ \\ ${ }^{1}$ Department of Chemistry, Technical University of Denmark, Kongens Lyngby, Region Hovedstaden, 2800 Denmark. \\ ${ }^{2}$ Institute of Molecular Medicine, Sechenov First Moscow State Medical University, Moscow, 119991 Russia. ${ }^{3}$ DTU Food, \\ Technical University of Denmark, Kongens Lyngby, Region Hovedstaden, 2800 Denmark. ${ }^{4}$ Department of Pediatrics, \\ Program in Immunology, Stanford University School of Medicine, Stanford, California, 94305 United States of America. \\ *Corresponding author E-mail: kiraas@kemi.dtu.dk (KA)
}

\begin{abstract}
Multiple drugs have been proposed for reducing harsh symptoms of human rheumatic diseases. However, a targeted therapy with mild to no side-effects is still missing. In this study, we have prepared and tested a series of therapeutic nanoparticles for specific targeting of human neutrophils associated with rheumatoid arthritis. In doing this, a series of citrullinated peptide epitopes derived from human proteins fibrinogen, vimentin and histone 3, were screened with regard to specific recognition of neutrophils. The most potent epitope proved to be a mutated fragment of an alpha chain in human fibrinogen. Next, a straightforward synthetic strategy was developed for nanoparticles decorated with this citrullinated peptide epitope and an antisense oligonucleotide targeting disease associated microRNA miR-125b-5p. Our study shows that the nanoparticles specifically recognize neutrophils and knock down miR-125b-5p, with no apparent toxicity to human cells. In contrast to organic dendrimers, chitosan-hyaluronic acid formulations do not activate human innate immune response. Our data proves that the strategy we report herein is effective in developing peptide epitopes for decorating delivery vehicles bearing biological drugs, targeted to a specific cell type.
\end{abstract}

\section{Introduction}

Today, rheumatoid arthritis (RA) is a life-long diagnosis for over 100 million people worldwide. ${ }^{1,2}$ Existing therapies reduce the symptoms of RA, however they do not prevent a disease progression leading to physical disability in over 50\% RA patients. ${ }^{3,4}$ This poses a clear challenge for existing treatment and promotes the development of alternative approaches, including therapeutic antibodies and synthetic nanomaterials. ${ }^{5,6}$

Neutrophils are the most abundant white blood cells in humans. Approximately 1011 neutrophils are produced daily which accounts for approximately $50-70 \%$ of all leukocytes. Emerging evidence suggests that neutrophils also have a previously unrecognized role in RA. ${ }^{7}$ For example, citrullinated proteins that can act as neoepitopes in loss of immune tolerance are generated enzymatically within neutrophils. Citrullination of arginine in peptides and proteins (Figure 1A) has been extensively studied in the last two decades as a biomarker of autoimmune diseases. ${ }^{8}$ The most commonly accepted molecular mechanism for citrullinated peptides/proteins in RA is that the modified antigen is derived from cell damage or uncontrolled apoptosis and evoke an immune response leading to autoantibodies against these peptide or the whole protein. Autoreactive antibodies to citrullinated peptides and proteins (ACPA) are associated with RA. ACPA recognize a variety of citrullinated antigens - prominent among them being citrullinated $\alpha$-enolase, vimentin, type II collagen, fibrinogen and histone. ${ }^{8}$ Notably, ACPA can be detected years before the onset of RA and are predictive of a severe disease. ${ }^{9}$ This makes citrullinated peptides an exciting object of studies for targeted drug delivery and a valuable diagnostic tool. ${ }^{8,9}$

Aiming at diagnostic and therapeutic applications, peptide libraries have been developed for discovery of better citrullinated epitopes. ${ }^{10}$
A)

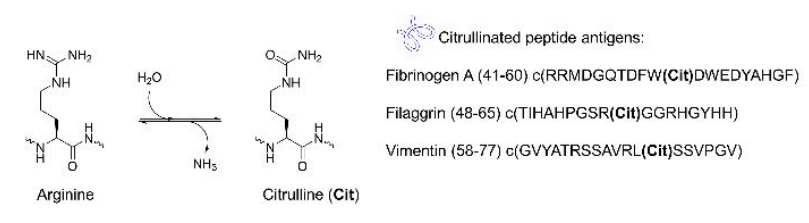

B)

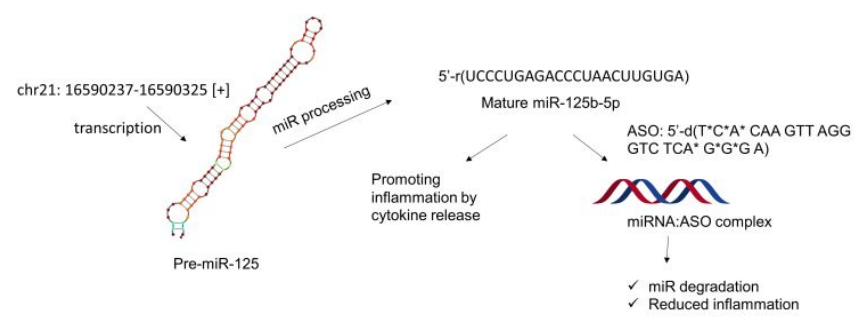

Figure 1. Biological basis for this work: Chemical structure of arginine, citrullin and examples of citrullinated peptides associated with rheumatoid arthritis (A). ${ }^{13-15}$ Pathway for miRNA-125 synthesis, maturation and its role in rheumatoid arthritis (B). ${ }^{18-20}$ ASO $=$ antisense oligonucleotide targeting miR-125b-5p.

Over the last decade, a $2^{\text {nd }}$ generation cyclic citrullinated peptide (CCP2) and $3^{\text {rd }}$ generation cyclic citrullinated peptide (CCP3) assays have been developed. Apart from the main difference in epitope, both CCP2 and CCP3 use enzyme-linked immunosorbent assay (ELISA) method. Most studies, however, show no evident improvement of CCP3 compared to CCP2 assays. Although CCP's are being applied in multiple fluorescent bead-based and cell sorting methods, ${ }^{10-12}$ their compositions are not yet publicly available as patents are pending. Information on the original proteins containing these $\mathrm{CCP}$ epitopes is missing as well. ${ }^{10}$ 
In general, RA is associated with synovial production of rheumatoid factor (RF), ACPA and with multiple inflammatory cytokines, including interleukin (IL)-1, IL-6, IL-17 and tumor necrosis factor (TNF)- $\alpha$, which are targets for RA therapeutics. ${ }^{13-15}$ A growing body of research points to a role of small regulating RNA, microRNA, in pathogenesis of RA. ${ }^{16-18}$ miRNA are short, hairpin nucleic acids, that bind regulatory mRNA regions and regulate gene expression by either increasing or inhibiting mechanisms. Specifically, miR-226 and miR-125 are two molecules that are overexpressed in RA (Figure 1B). ${ }^{18}$ Blocking these miRNA by e.g. antisense or RNA interference (RNAi) approaches could become an emerging treatment option for RA. ${ }^{19,20}$ However, one of the major issues with biological therapies including gene therapy is poor drug delivery options and low tissue specificity, leading to poor therapeutic performance and/or severe side effects. ${ }^{21}$

Choosing a suitable delivery method is therefore a crucial aspect for biological therapies. ${ }^{22}$ Organic nanoparticles improve stability and uptake of otherwise rapidly degraded biological drugs, e.g. antisense DNA (ASO), small interfering RNA (siRNA), and peptides. ${ }^{23}$ PAMAM and PNIMAM nanoparticles have been explored as therapeutic approaches for rheumatic diseases. ${ }^{23}$ However, specific cellular targeting has not yet been achieved. ${ }^{24}$ Other issues reported for organic nanoparticles include high polydispersity, toxicity and instability. ${ }^{24}$ As an alternative to organic polymers, natural carbohydrates are being actively explored as carriers for peptides and ASO, also in RA. A recent study successfully demonstrated the delivery of small interfering RNA (siRNA) by chitosan-hyaluronic acid nanoparticles. ${ }^{25}$ By specific targeting of macrophages, siRNA specifically knocked down overexpressed TNF- $\alpha$, and reduced inflammation. ${ }^{25}$

Herein, we hypothesized that a specific citrullinated peptide epitope can be selected by screening of protein fragments and their mutated variants in RA sera. Our second hypothesis was that by means of a suitable nanoparticle formulation, and by introducing the active citrullinated peptide epitope, specific delivery of gene therapeutic to human immune cells could be achieved. To test our hypotheses, we screened a library of citrullinated peptide epitopes derived from fibrinogen, vimentin and histone 3. Having selected the most potent peptide epitope, we included it into nanoparticles loaded with antisense oligonucleotide targeting RA associated microRNA. The structure and properties of the nanoparticles have been evaluated by a series of in vitro assays, ${ }^{22,26,27}$ and the most potent nanoparticles for specific targeting of human neutrophils in RA has been identified.

\section{Results and discussion}

\section{Defining autoimmune peptide epitope}

In autoimmune diseases, epitope-antibody binding is a potent strategy to facilitate specific uptake of a drug. ACPA in particular are intriguing receptors presented on $\mathrm{B}$ cells and in circulation that are related to immune hyper-activation in RA. ${ }^{10-}$ 12 Our initial goal was therefore to identify an effective citrullinated peptide epitope for targeting RA associated cells. Table S1 (SI, section S1), show the selected twenty-five peptide sequences that were screened in this work. The citrullinated peptide epitopes belong to three major groups, based on the protein they are derived from: fibrinogen (PEP1-PEP14), vimentin (PEP15-PEP20) and histone 3 (PEP21-PEP25) derived peptides. All selected peptide sequences were chosen based on previously reported and confirmed activity in RA. ${ }^{10-12}$ Vimentin and fibrinogen are often mutated among individuals diagnosed with RA. ${ }^{12}$ To take this into account, the mutated sequence variants for fibrinogen and vimentin have been recognized using BSI SPIDER homology search software. ${ }^{28}$ The sequences that were confirmed as mutated homologs to the original protein epitopes, were included into this study (SI, Table S1).

A)

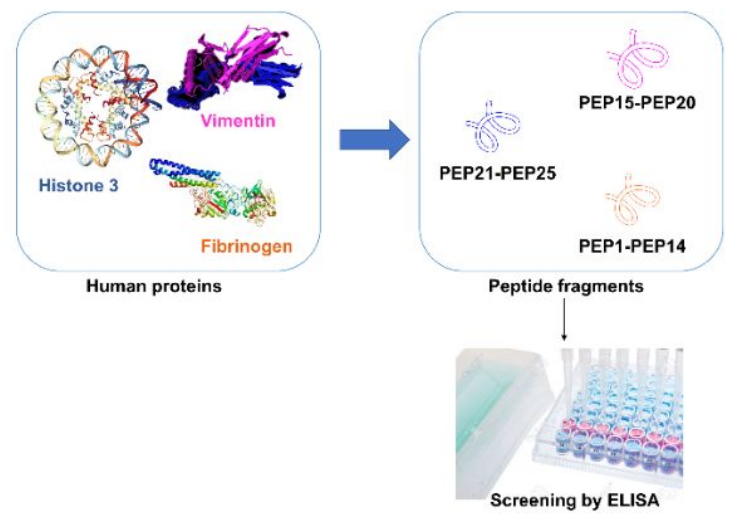

B)

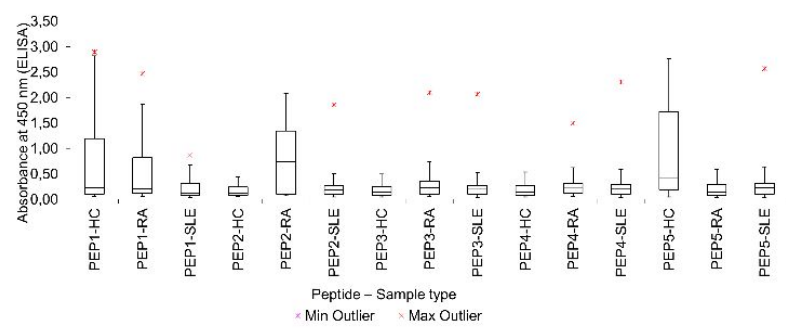

C)

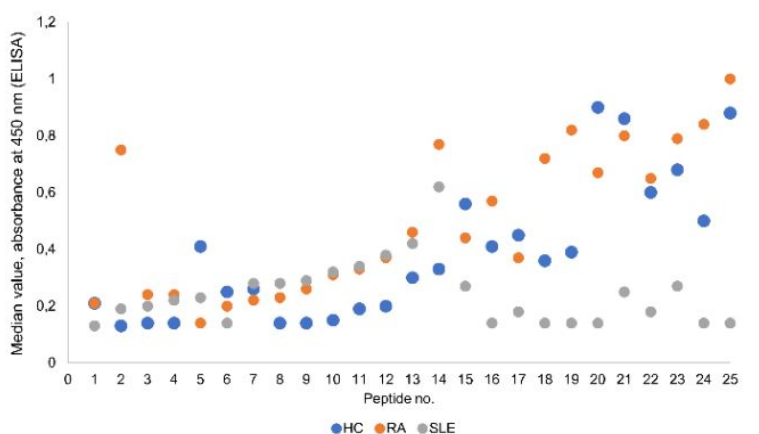

Figure 2. (A) General principle for design of peptide epitope candidates PEP1-PEP25. (B) Box-plot with outliers for absorbance values obtained by indirect ELISA (IgG) for PEP1-PEP5. For the data on PEP6-PEP25, see SI, section S2. (C) Median values for absorbance obtained by ELISA, PEP1-PEP25. HC = healthy control, RA = rheumatoid arthritis; SLE = systemic lupus erythematosus.

Citrullinated peptide antigens PEP1-PEP25 (free amine and carboxy-termini) have been screened in ELISA with sera of 30 
RA patients, 30 healthy controls and 30 patients with systemic lupus erythematosus (SLE) used as a control rheumatic disease (SI, Table S2). The results are shown in Figure 2, and in SI, section S2. Overall, 16 peptide antigens (53\%), from all three groups, recognized RA sera. However, histone 3 derived PEP21-PEP25 showed elevated signal in $17-23 \%$ healthy controls. Multiple fibrinogen derived peptides showed high recognition rate of RA sera but also of a control disease SLE (10-57\% and 7-23\%), whereas vimentin peptides had lower binding levels in RA (23-30\%). From this data we concluded that fibrinogen is the most potent parent protein for determining citrullinated peptide epitopes.

Next, we compared mutated fibrinogen and vimentin epitopes to native proteins. Prior to ELISA, the mutated epitopes were confirmed to be homologs of the native proteins in NCBI BLAST, with identity score $90-100 \%$ (SI, section S2, Figure S1). In ELISA, especially mutations in fibrinogen epitopes had a great effect on antibody recognition (see SI, Table S2, data for PEP1 vs. PEP2-PEP3, and PPE6 vs. PEP7-PEP8). On the contrary, mutations in vimentin epitopes had minor to no effect on ACPA binding levels. To the best of our knowledge, this is the first report showing the high influence of mutations within fibrinogen epitopes on ACPA binding. Lastly, BSI algorithm identified no mutants in the histone 3 derived sequences, which is in agreement with the observation that histones are highly conserved proteins that rarely mutate. ${ }^{12}$

Among all tested peptide epitopes, PEP2 with the sequence $\mathrm{H}_{2} \mathrm{~N}-\mathrm{HHP}$ GIA EFP S(Cit)G KSY SYS KQF-OH, Cit = citrullin, demonstrated high binding in RA samples (57\%), and low to no binding in healthy controls and SLE $(0 \%$ and $7 \%$; data shown in SI, Table S2 and Fig. S2). This is in line with previous reports suggesting high relevance of citrullinated fibrinogen to RA. ${ }^{29}$ Inspired by this result we applied PEP2 in the following study as an active epitope promoting a specific cell recognition.

\section{Nanoparticles containing gene therapeutic and citrullinated peptide epitope: synthesis and properties}

In the second part of this study, we developed nanoparticle formulations containing PEP2 and an antisense oligonucleotide (ASO) that specifically recognizes an RA associated microRNA miR-125b-5p, with the sequence: 5'r(UCCCUGAGACCCUAACUUGUGA)-3', according to miRNAbase (Figure 1B). ${ }^{6,30}$ MiR-125b-5p is upregulated in RA immune cells. We therefore aimed to knock down miR-125b$5 \mathrm{p}$ whereby decreasing inflammatory activity of the cells. ${ }^{30}$ PEP2 was synthesized in-house and used in protected form to ensure selective coupling between the $\mathrm{C}$-terminal of the peptide and the polymer core. Peptide synthesis is described in SI, section 3 .

For encapsulation of the ASO and PEP2, we chose two formulations: organic G5 PAMAM dendrimer and a chitosanhyaluronic acid (Figure 3). PAMAM is well characterized, it is biocompatible and easy to be covalently modified via terminal amino-groups. ${ }^{31}$ Despite numerous drug delivery applications, including nucleic acid therapeutic candidates, dendrimers have limitations, including rapid systemic clearance, difficulty in drug release, and toxicity because of its cationic groups..$^{32}$ On the other hand, chitosan is considered as a promising technology for the delivery of gene therapeutics as well. Chitosan is inexpensive, non-toxic and non-immunogenic. ${ }^{33}$
The cationic nature of chitosan can be employed to form chitosan /nucleotide complex via electrostatic interaction, which protects nucleic acids from enzymatic degradation and enhances cellular uptake. ${ }^{34}$ Chitosan based drug delivery are widely used approach in biology, nanotechnology and medicine; however, its delivery efficiency of biologicalmolecules strongly depends on $\mathrm{pH}$, molecular structure, shape, size and the ratio of amino groups of cation and phosphate group of anions which limits its therapeutic use. ${ }^{35,36}$ To address this issue, different polyanionic counter-ions including heparin, sodium alginate and hyaluronic acid are incorporated to the delivery system. ${ }^{37}$

A)
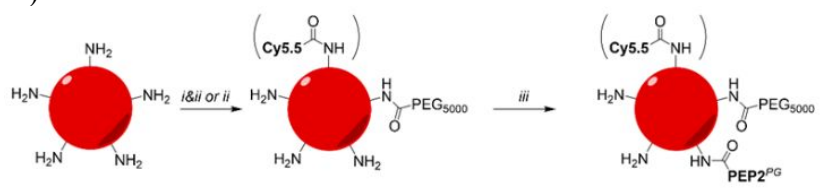

PAMAM G5 (1)
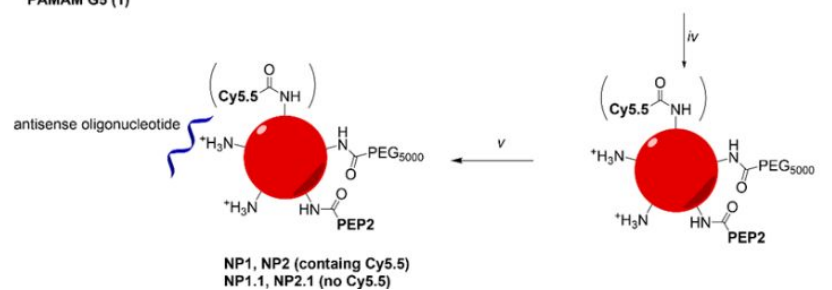

B)
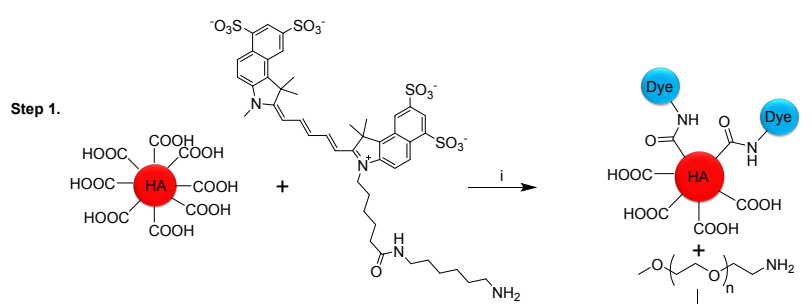

Step 2.
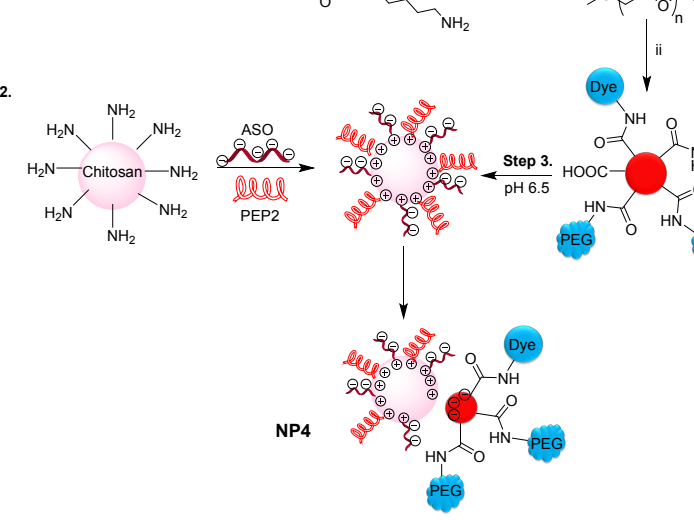

Figure 3. Synthesis and characterization of nanoparticles modified with epitope PEP2, derived from PAMAM (A) and chitosan-hyaluronic acid (B). Reaction conditions: (A) i. SulfoCy5.5 NHS, $100 \mathrm{mM}$ bicarbonate buffer, $\mathrm{pH}$ 8.3, room temperature, overnight; ii. mPEG-COOH $5 \mathrm{kDa}$; NHS/EDC; 100 $\mathrm{mM}$ bicarbonate buffer:DMF 4:1, v/v, $\mathrm{pH} 8.3$, room temperature, overnight; iii. PEP2, DMSO:MQ water 1:1 v/v, HOBt/EDC, $2 \mathrm{~h}$; iv. TFA $88 \%, \mathrm{H}_{2} \mathrm{O} 5 \%$, phenol $5 \%$, TIPS $2 \%, 8 \mathrm{~h}$, room temperature; v. ASO, MQ water, room temperature, 4 h; (B) Step 1. i. Sulfo-Cy5.5 amine, $100 \mathrm{mM}$ bicarbonate buffer, $\mathrm{pH} 8.3$, room temperature, $1000 \mathrm{rpm}, 6 \mathrm{~h}$; ii. mPEG-amine $5 \mathrm{kDa}$; NHS/EDC; $100 \mathrm{mM}$ bicarbonate buffer, $\mathrm{pH} 8.3$, room temperature, overnight. Step 2. Chitosan, ASO, PEP2, MQ water, $\mathrm{pH}$ 6.5, $1000 \mathrm{rpm}$, room 
temperature, $30 \mathrm{~min}$. Step 3. Product of step 1, product of step 2, MQ water, $\mathrm{pH} 6.5$, room temperature, $30 \mathrm{~min}$.

In this study we aimed at comparing these two well established systems, PAMAM and chitosan-hyaluronic acid, as carriers for both citrullinated peptide PEP2 and oligonucleotide ASO. Our synthetic approach is shown in Figure 3. The Synthesis share a similar approach for both polymer cores. Detailed description of the synthesis can be found in SI, section S3. The nanoparticles were synthesized with and without fluorophore labeling and the ASO, leading to a total of eight formulations plus a control with no polymer core as shown in Table 1 . In both cases, the ASO was non-covalently conjugated in order to allow release inside the cell.

As a first step, PAMAM derived nanoparticles NP1 and NP2 were fluorescently labelled with sulfo-Cy5.5 NHS ester. ${ }^{38}$ The fluorescamine assay showed conjugation by $5 \%$ or six of the terminal amines (SI, Fig. S5, Table S6). Further functionalization of PAMAM with $\mathrm{mPEG}-\mathrm{COOH} 5 \mathrm{kDa}$ was achieved through NHS/EDC reaction. MALDI MS showed a distribution of products with 1-10 PEG chains conjugated to the polymer, whereas the fluorescamine assay indicated $9 \%$ or 11 amines being conjugated with PEG (SI, section 4).

Table 1. Chemical composition, average diameter by NanoSight and SEM for the Cy5.5 labelled nanoparticles and controls.*

\begin{tabular}{|c|c|c|c|}
\hline Identifier & Conjugates & $\begin{array}{l}\text { Size by } \\
\text { NanoSight } \\
\text { (mean), nm }\end{array}$ & $\begin{array}{l}\text { Size by SEM } \\
\text { (mean), nm }\end{array}$ \\
\hline PAMAM & PAMAM & 119.9 & 87.3 \\
\hline NP1 & $\begin{array}{l}\text { PAMAM, } \\
\text { PEG, PEP2 }\end{array}$ & 129.5 & 228.0 \\
\hline NP2 & $\begin{array}{l}\text { PAMAM, Cy5.5, } \\
\text { PEG, PEP2, ASO }\end{array}$ & 260.4 & 216.0 \\
\hline Chitosan & Chitosan & 364.2 & 165.5 \\
\hline NP3 & $\begin{array}{l}\text { Hyaluronic acid, } \\
\text { Cy5.5, PEG }\end{array}$ & 122.9 & 150.8 \\
\hline NP4 & $\begin{array}{l}\text { Chitosan, } \\
\text { Hyaluronic acid, } \\
\text { Cy5.5, PEG, PEP2, } \\
\text { ASO }\end{array}$ & 185.6 & 605.0 \\
\hline NP5 & $\begin{array}{l}\text { Chitosan, } \\
\text { PEP2, ASO }\end{array}$ & 109.7 & 269.0 \\
\hline $\mathrm{C} 1$ & PEG, PEP2, ASO & - & \\
\hline
\end{tabular}

\footnotetext{
* Each data point is an average of two independent measurements
} with result deviation below $5 \%$.

In PAMAM, PEP2 was conjugated using a covalent strategy that has been previously reported for attachment of polyfunctional moieties to the amine-end of the polymer using HOBt and EDC. ${ }^{23}$ To ensure site-specific coupling, PEP2 was conjugated to PAMAM prior to the removal of the protecting groups. MALDI MS showed an increase in mass indicating 110 peptides had been conjugated (SI, Table S5). In this case, fluorescamine assay revealed an increase up to $21 \%$ conjugation of the terminal amines (SI, Table S6). Last, the ASO was efficiently encapsulated using a non-covalent method based on electrostatic interactions between the negatively charged oligonucleotide and positively charged amineterminals of PAMAM.$^{30}$ In order to quantify the encapsulation efficiency, the product was purified by $10 \mathrm{kDa}$ Amicon filtration and the ASO was released from the nanoparticle by incubating the sample at $90{ }^{\circ} \mathrm{C}$ in a $1 \%$ Tween-20 aqueous solution. The concentration of ASO was then measured using a HPLC standard curve, giving a complexation yield of $95 \%$ (SI, Figs. S6-S8 and Table S7).

For the chitosan-hyaluronic acid (CS-HA) nanoparticles, noncovalent encapsulation was used for both the ASO and PEP2 (Figure 3B). This is due to the fact that CS-HA actively binds both peptides and nucleic acids in a non-covalent fashion. ${ }^{25}$ Detailed description of the synthesis can be found in SI, section S3. In brief, CS-HA formulations were prepared by two-step encapsulation procedure. First, ASO and PEP2 were noncovalently encapsulated with chitosan, in $5 \%$ molar ratio each by mixing all 3 components. Secondly, hyaluronic acid was fluorescently labelled with sulfo-Cy5.5 amine. MALDI MS showed an increase in mass corresponding to two added fluorophores. $\mathrm{mPEG}$-amine $5 \mathrm{kDa}$ was then conjugated using NHS/EDC chemistry. Now MALDI MS confirmed a successful addition of two PEG chains (SI, Figs. S19-S22 and Table S5). The two functionalized polymers were then mixed in an equimolar ratio to form the final nanoparticles (SI, Figs. S9, S11 and S12; Table S6).

Our initial approach was to analyze the amounts of ASO and PEP2 by HPLC, similarly to PAMAM nanoparticles described above, usingTween-20 denaturation. However, no compound was released under a series of conditions (data not shown). Instead, the Amicon wash produced during the encapsulation was measured to show any unconjugated ASO and PEP2. Based on this the yields were determined to be $95 \%$ for the ASO and $32 \%$ for PEP2. Yields for non-covalent conjugation to chitosan have previously been reported to be $>95 \%$ for nucleotides and $75 \%$ for the peptide insulin. ${ }^{39,40} \mathrm{We}$ speculate that the lower encapsulation yields of PEP 2 can be caused by its lower charge and higher hydrophobicity compared to insulin.

Remarkably, for PAMAM, the synthetic procedures for PEP2 attachment and ASO encapsulation were the key factors affecting the yields and polydispersity. We found that 2 hours long PEP 2 coupling and 4 hour long ASO encapsulation under gentle shaking $(250 \mathrm{rpm})$ were the ideal conditions to achieve a low polydispersity, as determined by dynamic light scattering (DLS; SI, section S4, Table S3, DLS result for optimized conditions: NP2, size $294 \mathrm{~nm}$, polydispersity index (PDI) = 0.223 ). In turn, vigorous stirring and longer coupling times dramatically increased the undesired product polydispersity, with nanoparticle products over $1000 \mathrm{~nm}$ in size determined by DLS (SI, Table S3).

We further analyzed all product formulations by NanoSight and scanning electron microscopy (SEM). Compared to CS-HA, there was good agreement between NanoSight and SEM for PAMAM nanoparticles (Table 1). Furthermore, the standard deviation for PAMAM nanoparticles was higher than for CSHA (see SI, section S4). NanoSight revealed the size of PAMAM derived NP1 and NP2 as $129.5 \mathrm{~nm}$ and $260.4 \mathrm{~nm}$. The high values of standard deviation $(>100 \mathrm{~nm})$, indicated a broad structural distribution of the samples due to disordered assembly. Moreover, Cy5.5 might increase the PDI and affect 
the NanoSight measurement as the SD and size of PAMAM only is $43 \mathrm{~nm}$ and $119.9 \mathrm{~nm}$ respectively. ${ }^{41}$

SEM data for CS-HA nanoparticles differed from NanoSight, which is common. ${ }^{42}$ Sample preparation is different in NanoSight and SEM, which affect the results. The former is conducted in solution and the latter with dry sample, on the surface of a chip. Nevertheless, the effect of chemical composition on size shows similar trends by SEM and NanoSight. In general, SEM shows that the size nanoparticle and control was between $87 \mathrm{~nm}$ and $605 \mathrm{~nm}$, with a high effect of the surface decoration on the average diameter (Table 1). ${ }^{43}$ Particularly NP4 showed a high aggregation propensity by SEM (size $605 \mathrm{~nm}$ ). Upon drying of the sample, this heavily modified nanoparticle could be aggregating, in contrast to NP3 and NP5 that contain fewer modifications.

Binding of nanoparticles to human autoimmune antibodies was studied by ELISA with anonymized patient samples. Fluorescently labelled and non-labeled nanoparticle variants were immobilized on the surface of microtiter plates that were used in the indirect ELISA with a series of human samples. The samples were obtained from patients diagnosed with RA ( $\mathrm{n}=$ 40 ), systemic lupus erythematosus (SLE; $n=25$ ), and matched 60 healthy controls $(\mathrm{HC} ; \mathrm{n}=60)$; see SI, Table S5, for clinical and demographic information.

In ELISA, we observed a statistically significant difference between RA and controls for NP2 and NP4 ( $p<0.001$ by oneway ANOVA, R; data normally distributed for all groups, by Shapiro-Wilk W test). NP2 specifically recognized $44 \%$ of RA samples, with strong correlation to anti-CCP levels $(\mathrm{p}<0.0001$ by linear regression; SI, Figs. S41-S42). NP4 recognized $52 \%$ of RA samples, with a $91 \%$ overlap with NP2. NP1 and NP3 showed no binding of either RA or SLE sera, whereas a negative control $\mathrm{C} 1$ had a positive response in RA sera.

Interestingly, levels of antibodies to NP2 detected in RA samples correlated with typical biomarkers of the disease antinuclear antibody and rheumatoid factor (SI, Fig. S41). For a-NP4, levels were correlating with anti-citrullinated peptide antibodies but not with other biomarkers. This points to the important fact that the formulation affects interactions of the epitope with antibodies in serum. NP4 could have less exposed PEP2 epitope leading to lower reactivity. This could be beneficial for reduced unspecific binding, but could also lead to false negative results. In NP2, PEP2 is highly reactive and might detect cross-reacting antibodies such as those associated with antinuclear antibody and rheumatoid factor positivity.

Attachment of a fluorophore could potentially affect the recognition of epitope by antibody. ${ }^{44}$ To account for this, we compared fluorescently labeled nanoparticles and their unlabeled variants in ELISA (SI, section S6, Fig. S38, A compared to B). Our data shows that attachment of Cy5.5 leads to statistically significant difference in binding levels for neither PAMAM nor chitosan-hyaluronic acid based nanoparticles. This confirms no effect of the attached dye on antibody recognition by the nanoparticles. ${ }^{44}$ This is most likely due to the relatively low number of attached fluorophores per nanoparticle.

\section{Therapeutic activity of nanoparticles}

As a next step, we studied interactions of the nanoparticles NP1NP4 with primary human immune cells. This allowed us to mimic an intravenous (IV) administration and determine the recognition pattern of the nanoparticles by blood cells. ${ }^{45}$ For this, we applied flow cytometry analysis, which is a suitable method for tracking interactions of immune cells, and for purification of specific cell populations. ${ }^{45}$ In short, fresh donor blood was quickly processed and incubated with sulfo-Cy5.5labelled nanoparticles at concentrations ranging from $4 \mathrm{nM}$ to $0.5 \mathrm{nM}$. Blood cells were labeled with antibodies against different surface receptors to identify different immune cells, and the samples were analyzed by flow cytometry. Gating strategy for FACS data analysis can be seen in SI, Fig. S40.

According to our flow cytometry data, all nanoparticles showed dose-dependent interaction with primary cells (Figure 4). Herein, NP3 and NP4 showed more active interactions than PAMAM variants NP1 and NP2. T, B cells and NKs had much lower uptake of the nanoparticles than neutrophils and monocytes. After increasing the concentration from $1 \mathrm{nM}$ to 4 $\mathrm{nM}$, the discrimination of cells by NP2 and NP4 becomes more efficient (Figure 4C). C1 was not taken up by cells even at the highest concentration $(4 \mathrm{nM})$. This confirms the importance of delivery vehicles in therapy with "biologics", and points to promising properties of PAMAM and CS-HA in this regard. ${ }^{46,47}$

Importantly, the most efficient uptake was observed for nanoparticles containing PEP2. This means that the presence of PEP2 enhances specific cellular recognition by neutrophils. Given the fact that PEP2 is an epitope derived from fibrinogen, our data points to the presence of corresponding PEP2 receptors on the surface of neutrophils to successfully internalize the nanoparticles. This finding aligns with previous data on the role of fibrinogen in neutrophil activation, inflammation, activated phagocytosis and apoptosis. ${ }^{7}$

A comparison of PAMAM and chitosan-hyaluronic acid delivery systems has not been reported, although there are studies combining PAMAM and hyaluronic acid for siRNA delivery. ${ }^{23,25}$ Our study clearly points to the fact that efficiency of the epitope recognition depends on the nature of the vehicle, with higher recognition potential for chitosan-hyaluronic acid than PAMAM.

Next, to evaluate the biological activity of the ASO, human blood was incubated with the nanoparticles as described above, followed by cell sorting. Human neutrophils were collected and miR-125b-5p levels were measured by reverse transcription quantitative polymerase chain reaction, RT-qPCR. ${ }^{48}$ ASO-free NP1 and NP3, along with untreated neutrophils were used as negative controls. RT-qPCR showed that NP2 treatment at 4 $\mathrm{nM}$ decreased the levels of miR-125b-5p by over 6 -fold compared to negative controls (Figure 5). For NP4, a 3.5-fold decrease in miR-125b-5p expression was achieved at $4 \mathrm{nM}$. For NP1 and NP3, we have not observed a statistically significant difference in miR-125b-5p levels vs. not-treated control.

Together, the data in Figure 5 confirms the successful delivery of the ASO to primary human neutrophils by both PAMAM and chitosan-hyaluronic acid nanoparticles, in a dose-dependent manner, and with highest efficiency at $4 \mathrm{nM}$. 
A)

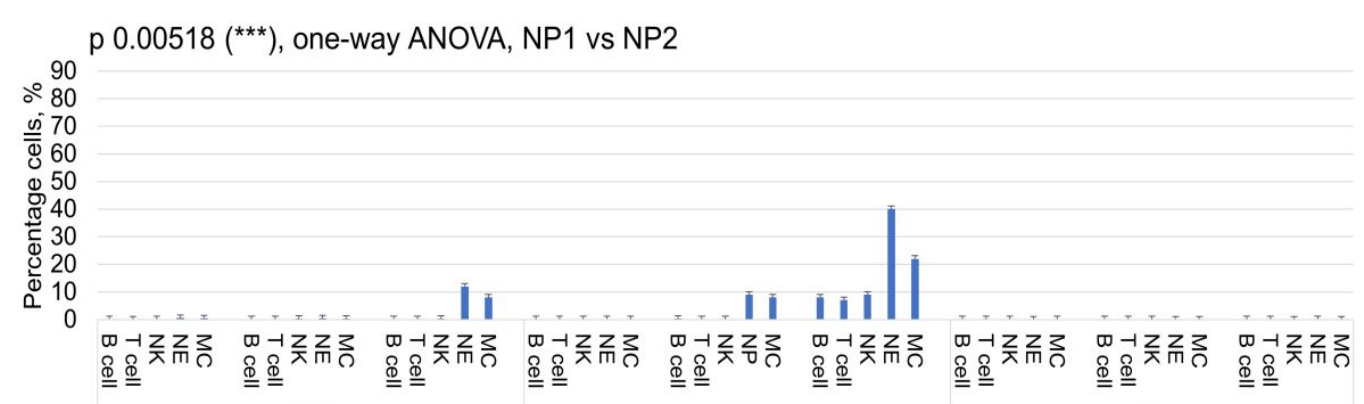

NP1

NP2

C1

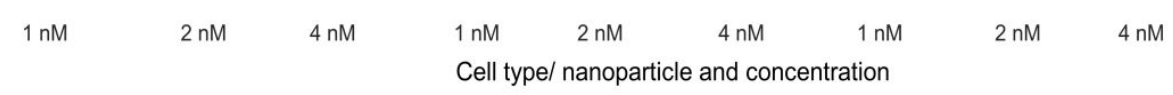

B)

p $\left.0.01{ }^{* *}\right)$, one-way ANOVA, NP3 vs NP4;

p $0.00045\left(^{* * *}\right)$, one way ANOVA, NP1+NP2 vs NP3+NP4

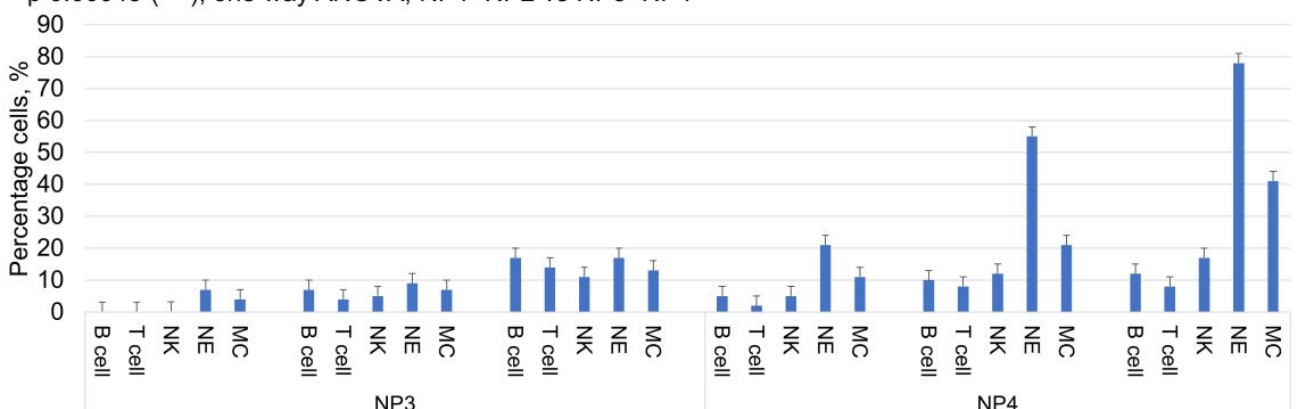

$\begin{array}{lllll}1 \mathrm{nM} & 2 \mathrm{nM} & 4 \mathrm{nM} & 1 \mathrm{nM} & \mathrm{nM}\end{array}$

Cell type/nanoparticle and concentration

C)

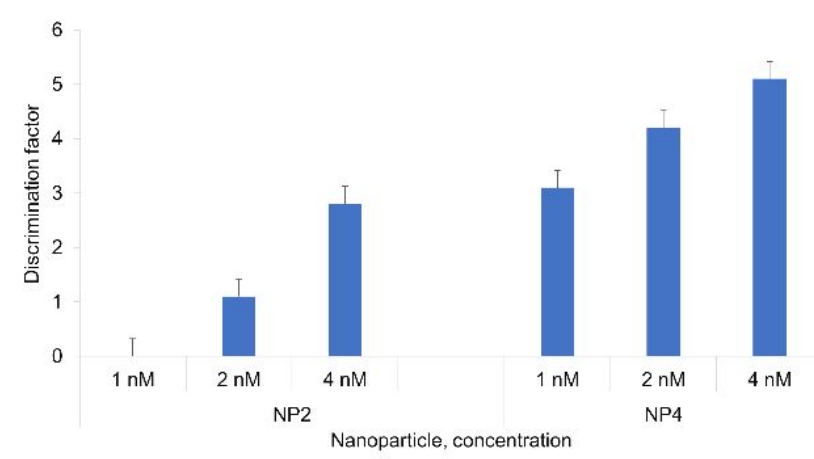

Figure 4. Nanoparticle recognition by neutrophil and monocyte population, studied by flow cytometry. Human blood was incubated with nanoparticles at designated concentration followed by flow cytometry staining and analysis. Frequency of nanoparticle-associated cells is shown (A,B); C). Discrimination of neutrophils (NE) by nanoparticles NP2 and NP4, calculated as the ratio of frequency of nanoparticle ${ }^{+}$ neutrophil to frequency of nanoparticle ${ }^{+}$monocytes, B, T and NK cells. Statistical analysis was done using one-way ANOVA in R. ** $95 \%$ significance; $* * * 99 \%$ significance. 


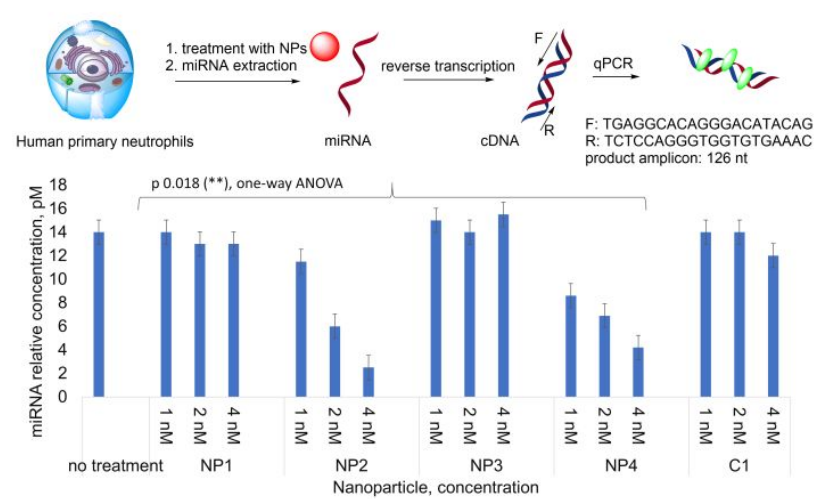

Figure 5. RT PCR of miR-125b-5p in primary human neutrophils. $F, R=$ forward, reverse primer.

\section{Toxicity studies in cells and blood}

To determine any potential toxicity, 23,25 we tested the nanoparticles and controls in a cell line and in primary immune cells (cell preparation described in SI, section S6). Cell viability was assessed using ATP luciferase test which is a straightforward, reliable method. ${ }^{49}$ NP1-NP4 and control C1 showed similar cell viability to PBS control, which confirms no apparent toxicity (SI, Fig. S39).

Following the cell viability assessment in cultured cells, we proceeded with testing the effect of developed nanoparticles on primary human cells in blood. Specifically, our goal was to determine if the epitope labeled nanoparticles activate the human complement system. Human complement is a part of an innate immune response that might affect the response to the drug. Peptides in particular have been reported as triggers of the complement system. ${ }^{50} \mathrm{We}$ tested for complement activation by measuring levels of $\mathrm{C} 3 \mathrm{~A}$ protein which is a product of a complement cascade reaction, after treating with nanoparticles (Figure 6) ${ }^{51}$ With little deviation among five individuals, the assay indicated no complement activation for chitosanhyaluronic acid nanoparticles NP3 and NP4 (Figure 6). On the contrary, PAMAM nanoparticles had a high concentration of complement activation products, pointing to potential issues in vivo. ${ }^{52}$

\section{Conclusions}

In conclusion, a panel of citrullinated peptide epitopes was screened for relevance to rheumatoid arthritis. We successfully identified PEP2 as the candidate, which showed the highest binding affinity and specificity in diseased human sera. PEP2 and an anti-miRNA-125b-5p gene therapeutic were incorporated in two types of nanoparticle formulations: PAMAM dendrimer and chitosan-hyaluronic acid. Both types of nanoparticles showed high cell targeting efficiency and are good vehicles for ASO delivery. Both ASO-loaded nanoparticles showed knock-down of the disease associated miRNA-125b-5p by the factor 3.5-6. The prepared nanoparticles also showed specific binding of RA sera
A)

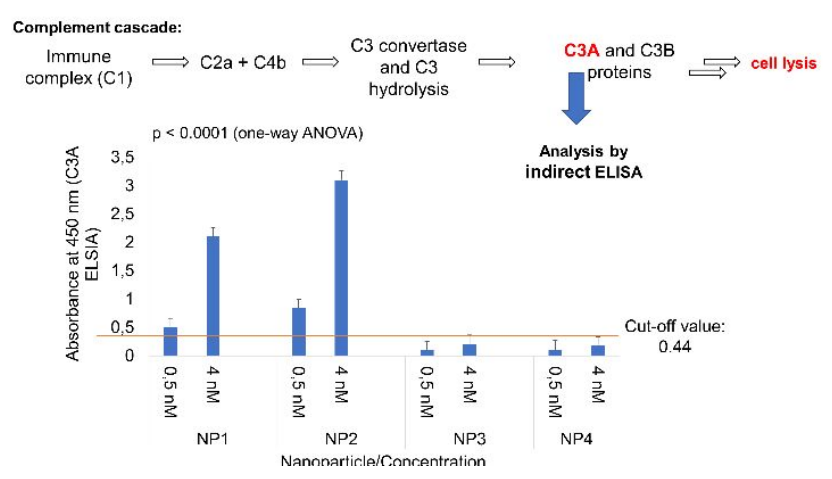

B)

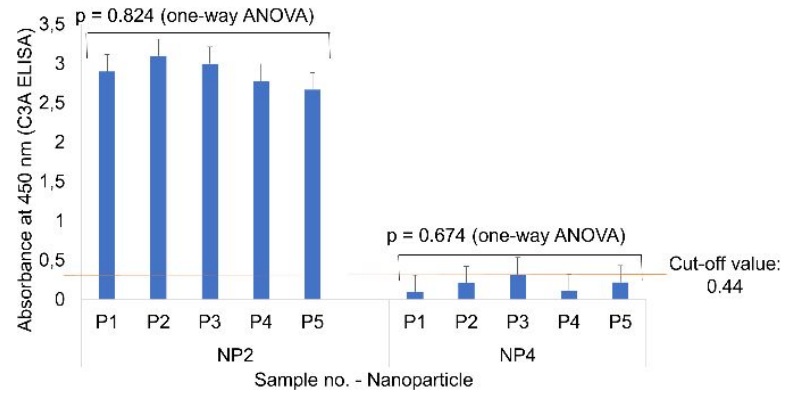

Figure 6. Complement activation test. A) General scheme of complement cascade showing key proteins and C3A generation, and results for C3A levels measured by indirect ELISA. Incubation of NP1-NP4 with human blood were conducted in $0.5 \mathrm{nM}$ and 4 $\mathrm{nM}$ concentrations; B) Patient variation study for five blood donors, $4 \mathrm{nM}$ concentration of NP2 and NP4. Cut-off value for negative control and 1:1500 blood dilution has been 0.44 .

compared to healthy subjects and systemic lupus erythematosus, used as negative control. Exclusively chitosanhyaluronic acid nanoparticles showed no apparent toxicity and no complement activation in human blood. With these properties, the nanoparticles reported herein show high potential as a new generation therapeutic candidates for human diseases in which neutrophils play a pathological role, such as rheumatoid arthritis.

\section{Methods}

A partially phosphorothioated ASO $\left(5^{\prime}-\mathrm{T}^{*} \mathrm{C}^{*} \mathrm{~A} *\right.$ CAA GTT AGG GTC TCA* $G^{*} \mathrm{G}^{*} \mathrm{G}$ A-3', where phosphorothioated nucleotides are shown with a star) was purchased from IDT, CA, USA. Sulfo-Cy5.5 NHS and sulfo-Cy5.5 amine reagents were kindly provided by Lumiprobe GmbH, Germany. mPEGAA (mPEG-Acetic Acid, mPEG-COOH) $5 \mathrm{kDa}$, mPEG amine $5 \mathrm{kDa}$ and low molecular weight hyaluronic acid $(10 \mathrm{kDa})$ were purchased from Creative PEGworks, USA. Amicon devices and dialysis membranes with various cut off values were purchased from Thermo Fisher Scientific. Other chemicals and solvents were obtained from Sigma Aldrich and used without further purification.

Synthesis and characterization of peptides and peptidemodified nanoparticles are described in SI, sections S1-S4. 
Patient sera for ELISA was provided by Statens Serum Institute (SSI), Copenhagen, Denmark. Donor blood for fluorescence assisted cell sorting (FACS), and for complement activation studies was obtained from Stanford University Hospital, CA, USA. Details on patient samples used in this study can be found in SI, section S5.

Fluorescamine assay has been applied for quantification of primary amines in PAMAM nanoparticles. The reaction of primary amines with fluorescamine yields a fluorescent derivative of which the fluorescence intensity can be used to determine the amino group content. ${ }^{26}$ The intensity is compared to a standard curve prepared with a series of PAMAM and fluorescamine dilutions. A stock solution of PAMAM (1 $\mathrm{mg} / \mathrm{mL}$ in MQ water) was prepared. A series of dilutions from 0-128 picomoles were prepared from the stock solution. Then, fluorescamine (Sigma, > $97 \%$ ) was added to each dilution in a mole ratio of 1:50. Fluorescence of labelled PAMAM nanoparticles was measured at excitation wavelength of $390 \mathrm{~nm}$ and emission wavelength of 475-490 nm using an UV-VIS spectrophotometer, Infinite 200 PRO (TECAN, Switzerland).

HPLC analysis was performed on a Dionex UltiMate 3000 system equipped with a Thermo Scientific, Hypersil GOLD C18 column $(5 \mu \mathrm{M}, 175 \AA, 150 \times 4.6 \mathrm{~mm})$. A liner gradient was used, running from 5 to $25 \%$ Buffer B in Buffer A, with a flow of $0.8 \mathrm{~mL} / \mathrm{min}$. over $30 \mathrm{~min}$. Signal detection was performed by an UltiMate 3000 VWD, measuring the absorbance of UV-light at $214 \mathrm{~nm}$ for peptides and $280 \mathrm{~nm}$ for oligonucleotides. Semipreparative HPLC purification was performed on the same system, running the same gradients. HPLC buffers were as follows: Oligo Buffer A: Aqueous 0.05M Triethylammonium acetate (TEAA), pH 7.4. Oligo Buffer B: $75 \% \mathrm{CH}_{3} \mathrm{CN}$ with 25 $\%$ Oligo Buffer A. Peptide Buffer A: $\mathrm{H}_{2} \mathrm{O}$ with $0.1 \%$ formic acid. Peptide Buffer B: $\mathrm{CH}_{3} \mathrm{CN}$ with $0.1 \%$ formic acid.

MALDI-TOF MS analysis was performed using an Autoflex speed MALDI-TOF mass spectrometer (Bruker Daltonics, Germany). A MTP 384 spot, polished steel target plate was used. Three different matrix compounds were used; 2,5dihydroxybenzoic acid (DHB), 2',4',6'-trihydroxyacetophenone monohydrate (THAP) and $\alpha$-cyano-4-hydroxycinnamic acid. Matrix solutions were prepared by dissolving $10 \mathrm{mg}$ of the corresponding reagent in $1 \mathrm{~mL} 70 / 30 \mathrm{CH}_{3} \mathrm{CN} / \mathrm{H}_{2} \mathrm{O}$ containing $0.1 \% \mathrm{TFA}(\mathrm{v} / \mathrm{v} / \mathrm{v}) .1 \mu \mathrm{L}$ sample and $1 \mu \mathrm{L}$ matrix mixture were spotted on the target plate and allowed to co-crystallize at room temperature. The resulting MS data was analyzed by the FlexAnalysis 3.4 (Bruker Daltonics, Germany) software.

DLS. Nanoparticles and controls $(0.5 \mathrm{mg} / \mathrm{mL})$ were sonicated (3 minutes) prior to each measurement to remove air bubbles or to avoid agglomerates. Afterwards, the samples $(30 \mu \mathrm{L})$ were filled in disposable cuvettes and three measuring cycles for each sample were carried out using Malvern Zetasizer Nano ZS and analyzed by zetasizer software.

NanoSight measurements were performed using Nano sight equipment NTA Version: NTA 3.1 Build 3.1.46 with Script SOP Standard Measurement 03-47-19PM 20D. The sample cell was removed from the device and thoroughly cleaned by ethanol and Millipore water prior to use. A diluted sample (0.5 $\mathrm{mL}$ ) was injected three times for three runs and the concentration of nanoparticles was adjusted using MQ water.
The size distribution data and the size with maximum number of particles were recorded.

The morphology of the nanoparticles was investigated using a Quanta FEG 3D scanning electron microscope SEM). Samples were attached on metal stubs with double-sided adhesive carbon tape and coated with $6 \mathrm{~nm}$ of gold for better conductivity using a sputter coater (Leica Coater ACE 200). The average nanoparticle diameter was calculated using Image $\mathrm{J}$ analysis software (National Institutes of Health, MD, USA). Each image has been analyzed at 10 different points, and the average diameter obtained by these measurements is given for each nanoparticle.

ELISA procedure was adopted from the paper by Samuelsen, Maity et al. ${ }^{27}$ Maxisorb 96 well plates (NUNC Thermofisher) were coated with nanoparticle antigens/controls at aconcentration of $8 \mu \mathrm{g} / \mathrm{mL}$ in $1 \mathrm{X}$ PBS overnight (room temperature; $100 \mu \mathrm{l} /$ well $)$. After washing with $1 \mathrm{X}$ PT $(2 \times 300$ $\mu \mathrm{l}$ /well, PT: $50 \mu \mathrm{l}$ Tween-20 in $1 \mathrm{~L} 1 \mathrm{X}$ PBS), the plates were blocked with 1 X PTB $\left(1 \mathrm{~h}, 37^{\circ} \mathrm{C} ; 100 \mu \mathrm{l} /\right.$ well, PTB: $20 \mathrm{~g} \mathrm{BSA}$, $50 \mu \mathrm{l}$ Tween-20 in $1 \mathrm{~L} 1 \mathrm{X}$ PBS). Incubation with plasma at desired dilution was performed at room temperature for $1.5 \mathrm{~h}$ using diluent: $2 \mathrm{~g}$ BSA, $50 \mu \mathrm{l}$ Tween-20 in $1 \mathrm{~L} 1 \mathrm{X}$ PBS (100 $\mu 1 /$ well). This was followed by washing $(2 \times 300 \mu 11 \mathrm{X}$ PBS $)$ and incubation with HPR-labelled secondary antibody for $1.5 \mathrm{~h}$ at room temperature using same diluent and dilution of the secondary antibody provided by supplier (HPR-conjugated aaIgG; Sigma). Subsequent washing $(2 \times 300 \mu \mathrm{l}$ PT) and incubation with freshly prepared TMB- $\mathrm{H}_{2} \mathrm{O}_{2}$ solution (Sigma; $100 \mu \mathrm{l} /$ well) was followed by adding a stop solution (1M $\mathrm{H}_{2} \mathrm{SO}_{4} ; 50 \mu \mathrm{l} /$ well) and reading resulting absorbance values at $450 \mathrm{~nm}$ on Magellan Tecan microplate reader. Linear range for each antigen was determined via testing series of control dilutions (RA, SLE and healthy controls in dilutions 1:50 to 1:2000). According to the results plasma dilutions 1:100 - 1:500 were within linear range of the assay for each antigen $\left(\mathrm{R}^{2}>\right.$ 0.95).

\section{Primary human cell line study}

Venous blood samples collected in heparin tubes from healthy adult subjects were obtained anonymously from the Stanford Blood Center; the work was approved by the Administrative Panels on Human Subjects Research from Stanford University, CA, USA. Whole blood was diluted with an equal volume of RPMI 1640 and centrifuged at $400 \mathrm{~g}$ for $5 \mathrm{~min}$ at room temperature. The supernatant was removed by aspiration. The process was repeated twice. $250 \mu \mathrm{l}$ of the blood cell pellet was aliquoted for each reaction and RBC were lysed with ACK lysing buffer (Thermo Fisher, cat no. A1049201). RBCdepleted cells were washed with RPMI 1640 twice and resuspended in $250 \mu 1 \mathrm{RPMI} 1640$.

For nanoparticle incubation, a set volume of nanoparticles (250 $\mu \mathrm{l})$, previously diluted to the desired concentration in RPMI 1640 , was added to the RBC-depleted cell at a final volume of $500 \mu \mathrm{l}$, and the mixture was incubated for $30 \mathrm{~min}$ at $37^{\circ} \mathrm{C}$. The mixture was then transferred to ice for another $20 \mathrm{~min}$ and washed with RPMI 1640 once before flow cytometry staining.

\section{Flow cytometry staining and analysis}


The cell pellet was stained with LIVE/DEAD Aqua (1:1000 dilution in PBS, ThermoFisher Scientific) for $10 \mathrm{~min}$ at room temperature. Cells were then washed with flow buffer (DPBS supplemented with $1 \%$ BSA and $0.01 \% \mathrm{NaN}_{3}$ ) before blocking for nonspecific binding with flow buffer containing $5 \%$ heat inactivated $\mathrm{AB}$ serum (Corning) and $5 \%$ goat serum (ThermoFisher Scientific) for $15 \mathrm{~min}$. on ice. After blocking, cells were stained on ice for $30 \mathrm{~min}$. with the following fluorochrome-conjugated antibodies in an 8-color staining combination: Alexa Fluor 488-labeled anti-CD20 (clone 2H7); FITC-labeled anti-CD56 (clone HCD56); Pacific Blue-labeled anti-CD15 (clone W6D3); APC-labeled anti-CD3 (clone UCHT1); Brilliant Violet 785-labeled anti-CD14 (clone M5E2); Brilliant Violet 605-labeled anti-CD11b (clone ICRF44). All antibodies were purchased from Biolegend and were used at 1:50 final dilution. Nanoparticles conjugated with sulfo-Cy5.5 were detected in the APC-Cy5.5 channel (a 730/45 BP filter with a $685 \mathrm{LP}$ splitter at $640 \mathrm{~nm}$ Red laser). After wash, cells were fixed with $200 \mu$ l fixation buffer (Cytofix, BD Biosciences) followed by 2 washes with flow buffer and resuspension in $200 \mu \mathrm{l}$ flow buffer. Cells were analyzed on a Becton Dickinson LSRII Analyzer at Stanford Shared FACS facility. Data were analyzed using FlowJo version 10 (FlowJo LLC), and the gating strategy shown in SI Figure S40.

After the similar blood work up and incubation procedures, cell sorting was carried out using BD FACS Melody cell sorter, at DTU HealthTech, Denmark. The cells were afterwards treated with lysis buffer (Sigma, cat. no. MCL1), and the total RNA has been extracted and purified using Qiagen RNeasy mini kit.

RT PCR has been carried out using miSCRIPT Qiagen kit (cat no. 218073), following manufacturer's procedure and custom designed primers. cDNA was synthesized from $2 \mu \mathrm{g}$ total RNA, and quantification of product amplicon was conducted by SybrGreen qPCR, using the following primers: F: 5'd(TGAGGCACAGGGACATACAG)-3'; R: 5'd(TCTCCAGGGTGGTGTGAAAC)-3'. The assay has been run in triplicate on Light Cycler 480, Roche, in a 96 well plate format. The data has been analyzed using Roche qPCR software. The concentration of miR-125b-5p was calculated based on the quantification cycle $(\mathrm{Cq})$, and the relative expression levels were calculated as $2^{-\Delta \Delta \mathrm{Cq}}\left[\Delta \Delta \mathrm{Cq}=\mathrm{Cq}_{\text {miR-125b- }}\right.$ $5 \mathrm{p}-\mathrm{Cq}_{\mathrm{PC}}$, where $\mathrm{PC}=$ positive control], following normalization with reference to the quantification of positive control expression (USP2, ubiquitin specific peptidase 2, located on chromosome 11, upstream from miR-125b gene cluster).

Complement activation has been studied using commercial ELISA kit C3A (Life technologies, cat no. BMS2089), following the manufacturer's procedure. Luciferase cell viability kit has been purchased from Thermo Fisher (cat no. A22066).

Anti-citrullinated peptide antibody (ACPA), antinuclear antibody (ANA), and rheumatoid factor (RF) levels were measured by indirect ELISA using commercial kits: MyBiosource cat no. MBS9424490 (ACPA), MBS702970 (ANA), and MBS265671 (RF).

Statistical analysis (descriptive statistics, one-way ANOVA and Ordinary least squares (OLS) test) were carried out in R. Data normality for all data sets was confirmed by Shapiro-Wilk test carried out in R, see SI, section S7. Control group was healthy controls and systemic lupus erythematosus (SLE). P values below 0.05 were considered statistically significant (95\% confidence level).

\section{ASSOCIATED CONTENT}

Supporting Information. Details on epitope screening; synthesis and characterization of nanoparticles; details and supporting data for ELISA, toxicity assay and FACS; statistical analyses.

Funding sources. Authors SK, JH and KA received funding from Villum Foundation Grant 13152. SCH and EDM received funding from The Daylight Foundation.

\section{AUTHOR INFORMATION}

\section{Corresponding Author}

*kiraas@kemi.dtu.dk

ORCID

Kira Astakhova: 0000-0003-4878-0301

Notes

The authors declare no competing financial interest.

\section{ACKNOWLEDGMENT}

We are grateful to Prof. Dr. Niels H.H. Heegaard (Statens Serum Institute, Copenhagen, Denmark) for helpful discussions, guidance and clinical samples.

\section{REFERENCES}

(1) Acosta-Herrera, M., González-Serna, D., Martín, J. (2019) The Potential Role of Genomic Medicine in the Therapeutic Management of Rheumatoid Arthritis. J. Clin. Med. 8, 826.

(2) Boissier, M.-C., Semerano, L., Challal, S., SaidenbergKermanac'h, N., Falgarone, G. (2012) Rheumatoid Arthritis: From Autoimmunity to Synovitis and Joint Destruction. $J$. Autoimmun. 39, 222-228.

(3) Tully, S. E., Rawat, M., Hsieh-Wilson, L. C. (2006) Discovery of a TNF-alpha Antagonist Using Chondroitin Sulfate Microarrays. J. Am. Chem. Soc. 128, 7740-7741.

(4) Sardar, S., Andersson, Å. (2016) Old and New Therapeutics for Rheumatoid Arthritis: In Vivo Models and Drug Development. Immunopharmacol. Immunotoxicol. 38, 2-13.

(5) Pozsgay, J., Babos, F., Uray, K., Magyar, A., Gyulai, G., Kiss, É., Nagy, G., Rojkovich, B., Hudecz, F., Sármay, G. (2016) In Vitro Eradication of Citrullinated Protein Specific B-lymphocytes of Rheumatoid Arthritis Patients by Targeted Bifunctional Nanoparticles. Arthritis Res. Ther. 18, 15.

(6) Hendley, C. T., Fielding, L. A., Jones, E. R., Ryan, A. J., Armes, S. P., Estroff, L. A. (2018) Mechanistic Insights into Diblock Copolymer Nanoparticle-Crystal Interactions Revealed via in Situ Atomic Force Microscopy. J. Am. Chem. Soc. 140, 7936-7945.

(7) Kargl, J., Busch, S. E., Yang, G. H. Y., Kim, K.-H., Hanke, M. L., Metz, H. E., Hubbard, J. J., Lee, S. M., Madtes, D. K., McIntosh, M. W., et al. (2017) Neutrophils Dominate the Immune Cell Composition in Non-small Cell Lung Cancer. Nat. Commun. 8, 14381. 
$(8)$

Yamanaka, H., Tanaka, Y., Takeuchi, T., Sugiyama, N., Yuasa, H., Toyoizumi, S., Morishima, Y., Hirose, T., Zwillich, S. (2016) Tofacitinib, an Oral Janus Kinase Inhibitor, as Monotherapy or with Background Methotrexate, in Japanese Patients with Rheumatoid Arthritis: An Openlabel, Long-term Extension Study. Arthritis Res. Ther. 18, 34.

(9) Aggarwal, R., Liao, K., Nair, R., Ringold, S., Costenbader, K. H. (2009) Anti-citrullinated Peptide Antibody Assays and Their Role in the Diagnosis of Rheumatoid Arthritis. Arthritis Rheum. 61, 1472-1483.
(10) Burtea, C., Laurent, S., Sanli, T., Fanfone, D., Devalckeneer, A., Sauvage, S., Beckers, M.-C., Rorive, S., Salmon, I., Vander Elst, L., et al. (2016) Screening for Peptides Targeted to IL-7R $\alpha$ for Molecular Imaging of Rheumatoid Arthritis Synovium. Arthritis Res. Ther. 18, 230.

(11) Mondal, S., Thompson, P. R. (2019) Protein Arginine Deiminases (pads): Biochemistry and Chemical Biology of Protein Citrullination. Acc. Chem. Res. 52, 818-832.

(12) Real-Fernández, F., Pratesi, F., Migliorini, P., Rovero, P. (2019) Histone Protein Epitope Mapping for Autoantibody Recognition in Rheumatoid Arthritis. Methods Mol. Biol. $1901,221-228$.

(13) Deane, K. D., O’Donnell, C. I., Hueber, W., Majka, D. S., Lazar, A. A., Derber, L. A., Gilliland, W. R., Edison, J. D., Norris, J. M., Robinson, W. H., et al. (2010) The Number of Elevated Cytokines and Chemokines in Preclinical Seropositive Rheumatoid Arthritis Predicts Time to Diagnosis in an Age-dependent Manner. Arthritis Rheum. 62, 3161-3172.

(14) Myngbay, A., Bexeitov, Y., Adilbayeva, A., Assylbekov, Z., Yevstratenko, B. P., Aitzhanova, R. M., Matkarimov, B., Adarichev, V. A., Kunz, J. (2019) CTHRC1: A New Candidate Biomarker for Improved Rheumatoid Arthritis Diagnosis. Front. Immunol. 10, 1353.

(15) Proost, P., Struyf, S., Van Damme, J., Fiten, P., UgarteBerzal, E., Opdenakker, G. (2017) Chemokine Isoforms and Processing in Inflammation and Immunity. J. Autoimmun. $85,45-57$.

(16) Nemtsova, M. V., Zaletaev, D. V., Bure, I. V., Mikhaylenko, D. S., Kuznetsova, E. B., Alekseeva, E. A., Beloukhova, M. I., Deviatkin, A. A., Lukashev, A. N., Zamyatnin, A. A. (2019) Epigenetic Changes in the Pathogenesis of Rheumatoid Arthritis. Front. Genet. 10, 570.

(17) Huang, J., Zhao, L., Fan, Y., Liao, L., Ma, P. X., Xiao, G., Chen, D. (2019) The microRNAs miR-204 and miR-211 Maintain Joint Homeostasis and Protect Against Osteoarthritis Progression. Nat. Commun. 10, 2876.

(18) Simpson, L. J., Ansel, K. M. (2015) MicroRNA Regulation of Lymphocyte Tolerance and Autoimmunity. J. Clin. Invest. $125,2242-2249$.

(19) Yang, D.-W., Qian, G.-B., Jiang, M.-J., Wang, P., Wang, K.Z. (2019) Inhibition of microRNA-495 Suppresses Chondrocyte Apoptosis through Activation of the NF- $\mathrm{KB}$ Signaling Pathway by Regulating CCL4 in Osteoarthritis. Gene Ther. 26, 217-229.

(20) Tao, Y., Wang, Z., Wang, L., Shi, J., Guo, X., Zhou, W., Wu, X., Liu, Y., Zhang, W., Yang, H., et al. (2017)
Downregulation of miR-106b Attenuates Inflammatory Responses and Joint Damage in Collagen-induced Arthritis. Rheumatology 56, 1804-1813.

(21) Lee, Y.-M., Duh, Y., Wang, S.-T., Lai, M. M. C., Yuan, H. S., Lim, C. (2016) Using an Old Drug to Target a New Drug Site: Application of Disulfiram to Target the Zn-Site in HCV NS5A Protein. J. Am. Chem. Soc. 138, 3856-3862.

(22) Gupta, M. K., Martin, J. R., Werfel, T. A., Shen, T., Page, J. M., Duvall, C. L. (2014) Cell Protective, ABC Triblock Polymer-based Thermoresponsive Hydrogels with ROStriggered Degradation and Drug Release. J. Am. Chem. Soc. 136, 14896-14902.

(23) Wang, Y., Luo, Y., Zhao, Q., Wang, Z., Xu, Z., Jia, X. (2016) An Enzyme-Responsive Nanogel Carrier Based on PAMAM Dendrimers for Drug Delivery. ACS Appl. Mater. Interfaces 8, 19899-19906.

(24) Kono, K., Akiyama, H., Takahashi, T., Takagishi, T., Harada, A. (2005) Transfection Activity of Polyamidoamine Dendrimers Having Hydrophobic Amino Acid Residues in the Periphery. Bioconjug. Chem. 16, 208-214.

(25) Howard, K. A., Paludan, S. R., Behlke, M. A., Besenbacher, F., Deleuran, B., Kjems, J. (2009) Chitosan/siRNA Nanoparticle-mediated TNF-alpha Knockdown in Peritoneal Macrophages for Anti-inflammatory Treatment in a Murine Arthritis Model. Mol. Ther. 17, 162-168.

(26) Dung, T. H., Do, L. T., Loan, T. T., Yoo, H. (2015) Preparation and Biophysical Characterization of Poly(amidoamine) Dendrimer-Poly (acrylic Acid) Graft. $J$. Nanosci. Nanotechnol. 15, 684-687.

Samuelsen, S. V., Maity, A., Nybo, M., Macaubas, C., Lønstrup, L., Balboni, I. M., Mellins, E. D., Astakhova, K. (2016) Novel Phospholipid-Protein Conjugates Allow Improved Detection of Antibodies in Patients with Autoimmune Diseases. PLoS One 11, e0156125.

Peptide Mutations \& Homology Searching for de novo Sequences - BSI http://www.bioinfor.com/peptidemutations-homology-searching/ (accessed Jul 16, 2019).

Gunasekera, S., Fernandes-Cerqueira, C., Wennmalm, S., Wähämaa, H., Sommarin, Y., Catrina, A. I., Jakobsson, P.-J., Göransson, U. (2018) Stabilized Cyclic Peptides as Scavengers of Autoantibodies: Neutralization of Anticitrullinated Protein/peptide Antibodies in Rheumatoid Arthritis. ACS Chem. Biol. 13, 1525-1535.

Ambros, V., Bartel, B., Bartel, D. P., Burge, C. B., Carrington, J. C., Chen, X., Dreyfuss, G., Eddy, S. R., Griffiths-Jones, S., Marshall, M., et al. (2003) A Uniform System for microRNA Annotation. RNA 9, 277-279.

Win-Shwe, T.-T., Sone, H., Kurokawa, Y., Zeng, Y., Zeng, Q., Nitta, H., Hirano, S. (2014) Effects of PAMAM Dendrimers in the Mouse Brain after a Single Intranasal Instillation. Toxicol. Lett. 228, 207-215.

(32) Labieniec-Watala, M., Watala, C. (2015) PAMAM Dendrimers: Destined for Success or Doomed to Fail? Plain and Modified PAMAM Dendrimers in the Context of Biomedical Applications. J. Pharm. Sci. 104, 2-14.
Qiao, J., Sun, W., Lin, S., Jin, R., Ma, L., Liu, Y. (2019) Cytosolic Delivery of CRISPR/Cas9 Ribonucleoproteins for 
Genome Editing Using Chitosan-coated Red Fluorescent Protein. Chem. Commun. 55, 4707-4710.

(34) Zhang, W., Xu, W., Lan, Y., He, X., Liu, K., Liang, Y. (2019) Antitumor Effect of Hyaluronic-acid-modified Chitosan Nanoparticles Loaded with siRNA for Targeted Therapy for Non-small Cell Lung Cancer. Int. J. Nanomedicine 14, 5287 5301.

(35) Chakraborty, P., Ghosh, M., Schnaider, L., Adadi, N., Ji, W., Bychenko, D., Dvir, T., Adler-Abramovich, L., Gazit, E. (2019) Composite of Peptide-Supramolecular Polymer and Covalent Polymer Comprises a New Multifunctional, BioInspired Soft Material. Macromol. Rapid Commun. e1900175.

(36) Lallana, E., Rios de la Rosa, J. M., Tirella, A., Pelliccia, M., Gennari, A., Stratford, I. J., Puri, S., Ashford, M., Tirelli, N. (2017) Chitosan/hyaluronic Acid Nanoparticles: Rational Design Revisited for RNA Delivery. Mol. Pharm. 14, 2422 2436

(37) Pilipenko, I., Korzhikov-Vlakh, V., Sharoyko, V., Zhang, N., Schäfer-Korting, M., Rühl, E., Zoschke, C., Tennikova, T. (2019) pH-Sensitive Chitosan-Heparin Nanoparticles for Effective Delivery of Genetic Drugs into Epithelial Cells. Pharmaceutics, 11.

(38) Yu, M. K., Park, J., Jon, S. (2012) Targeting Strategies for Multifunctional Nanoparticles in Cancer Imaging and Therapy. Theranostics 2, 3-44.

(39) Mun, E. A., Hannell, C., Rogers, S. E., Hole, P., Williams, A. C., Khutoryanskiy, V. V. (2014) On the Role of Specific Interactions in the Diffusion of Nanoparticles in Aqueous Polymer Solutions. Langmuir 30, 308-317.

(40) Lallana, E., Rios de la Rosa, J. M., Tirella, A., Pelliccia, M., Gennari, A., Stratford, I. J., Puri, S., Ashford, M., Tirelli, N. (2017) Chitosan/hyaluronic Acid Nanoparticles: Rational Design Revisited for RNA Delivery. Mol. Pharm. 14, 2422 2436.

(41) Li, L., Yang, L., Li, M., Zhang, L. (2017) A Cell-penetrating Peptide Mediated Chitosan Nanocarriers for Improving Intestinal Insulin Delivery. Carbohydr. Polym. 174, 182-189.

(42) Bachurski, D., Schuldner, M., Nguyen, P.-H., Malz, A., Reiners, K. S., Grenzi, P. C., Babatz, F., Schauss, A. C., Hansen, H. P., Hallek, M., et al. (2019) Extracellular Vesicle Measurements with Nanoparticle Tracking Analysis - An Accuracy and Repeatability Comparison Between NanoSight NS300 and ZetaView. J. Extracell. Vesicles 8, 1596016.
(43) Ponce, A., Mejía-Rosales, S., José-Yacamán, M. (2012) Scanning Transmission Electron Microscopy Methods for the Analysis of Nanoparticles. Methods Mol. Biol. 906, 453471.

(44) Sakamoto, S., Putalun, W., Vimolmangkang, S., Phoolcharoen, W., Shoyama, Y., Tanaka, H., Morimoto, S. (2018) Correction to: Enzyme-linked Immunosorbent Assay for the Quantitative/qualitative Analysis of Plant Secondary Metabolites. J. Nat. Med. 72, 43 .

(45) Gottstein, C., Wu, G., Wong, B. J., Zasadzinski, J. A. (2013) Precise Quantification of Nanoparticle Internalization. ACS Nano 7, 4933-4945.

(46) Sago, C. D., Lokugamage, M. P., Islam, F. Z., Krupczak, B R., Sato, M., Dahlman, J. E. (2018) Nanoparticles That Deliver RNA to Bone Marrow Identified by in Vivo Directed Evolution. J. Am. Chem. Soc. 140, 17095-17105.

Jalani, G., Tam, V., Vetrone, F., Cerruti, M. (2018) Seeing, Targeting and Delivering with Upconverting Nanoparticles. J. Am. Chem. Soc. 140, 10923-10931.

(48) Chen, C., Tan, R., Wong, L., Fekete, R., Halsey, J. (2011) Quantitation of microRNAs by Real-time RT-qPCR. Methods Mol. Biol. 687, 113-134.

(49) Crouch, S. P., Kozlowski, R., Slater, K. J., Fletcher, J. (1993) The Use of ATP Bioluminescence as a Measure of Cell Proliferation and Cytotoxicity. J. Immunol. Methods 160, $81-88$.

(50) Mohan, R. R., Cabrera, A. P., Harrison, R. E. S., Gorham, R. D., Johnson, L. V., Ghosh, K., Morikis, D. (2016) Peptide Redesign for Inhibition of the Complement System: Targeting Age-related Macular Degeneration. Mol. Vis. 22, $1280-1290$.

(51) Immunobiology - Immunobiology The Immune System in Health and Disease 5th edition Janeway CA Jr Travers P Walport $M$ et al New York Garland Science 2001 https://www.coursehero.com/file/7913575/Immunobiology/ (accessed Jul 16, 2019).

(52) Lin, J., Hua, W., Zhang, Y., Li, C., Xue, W., Yin, J., Liu, Z., Qiu, X. (2015) Effect of Poly(amidoamine) Dendrimers on the Structure and Activity of Immune Molecules. Biochim. Biophys. Acta 1850, 419-425. 


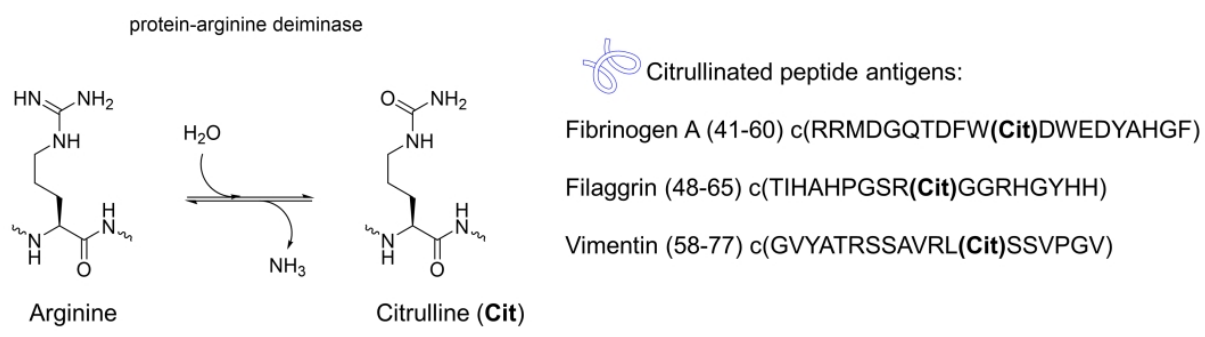

Figure 1A. Biological basis for this work: Chemical structure of arginine, citrullin and examples of citrullinated peptides associated with rheumatoid arthritis 


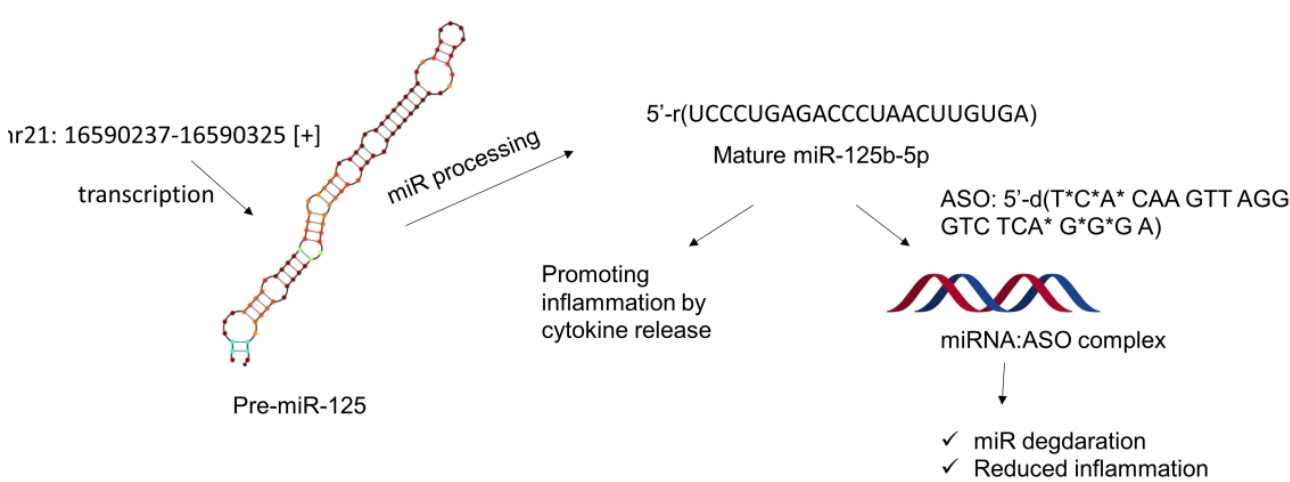

Figure 1B. Biological basis for this work: pathway for miRNA-125 synthesis, maturation and its role in rheumatoid arthritis. ASO = antisense oligonucleotide targeting miR-125b-5p. 


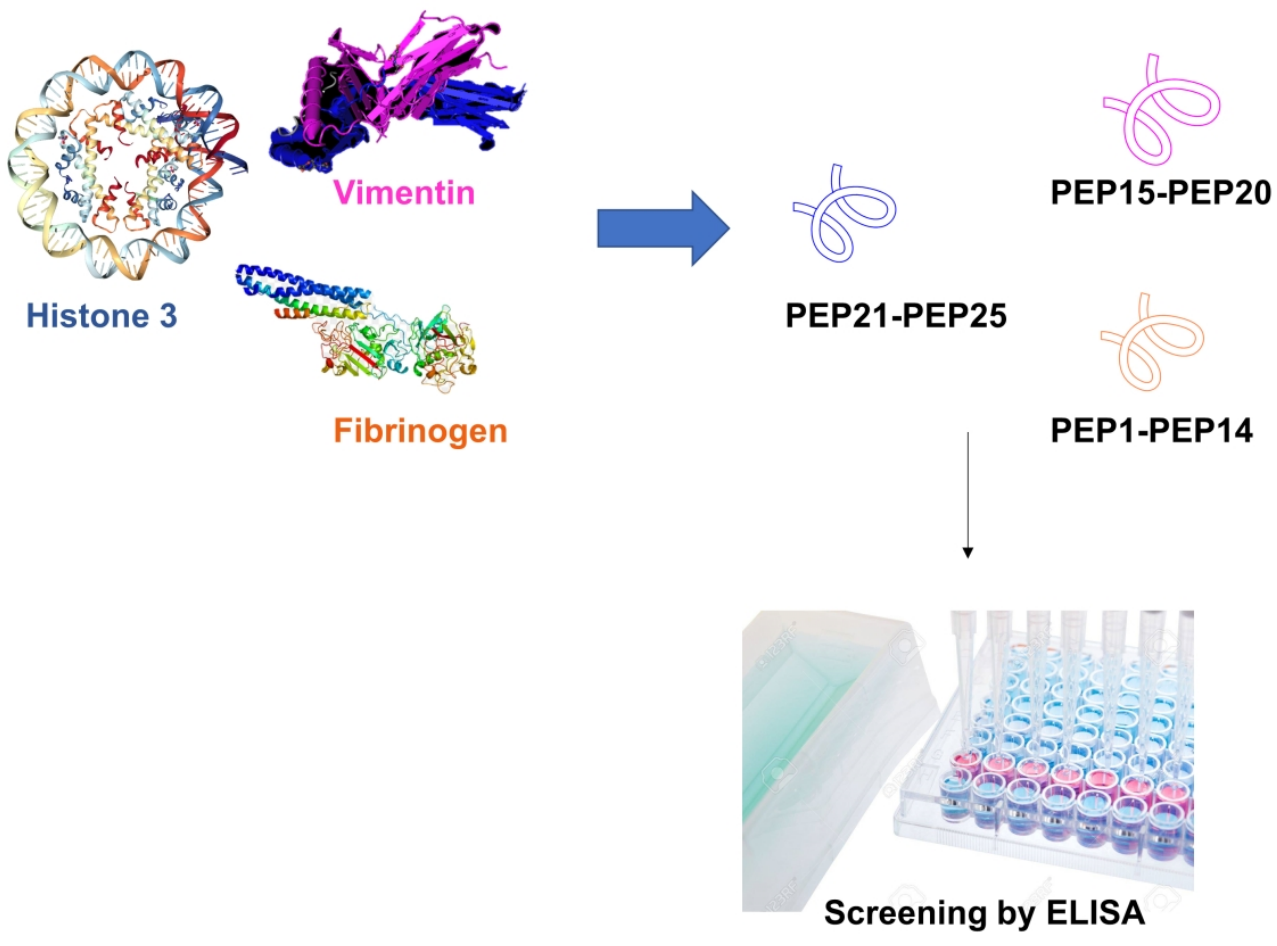

Figure 2A. General principle for design of peptide epitope candidates PEP1-PEP25. 


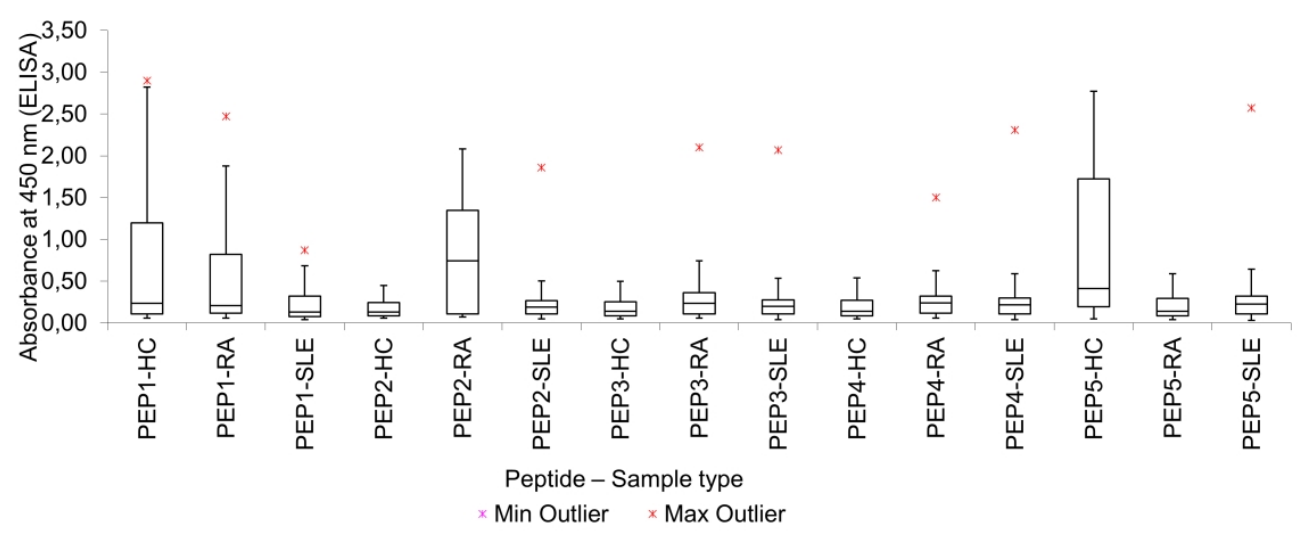

Figure 2B. Box-plot with outliers for absorbance values obtained by indirect ELISA (IgG) for PEP1-PEP5. HC = healthy control, RA = rheumatoid arthritis; SLE = systemic lupus erythematosus. 


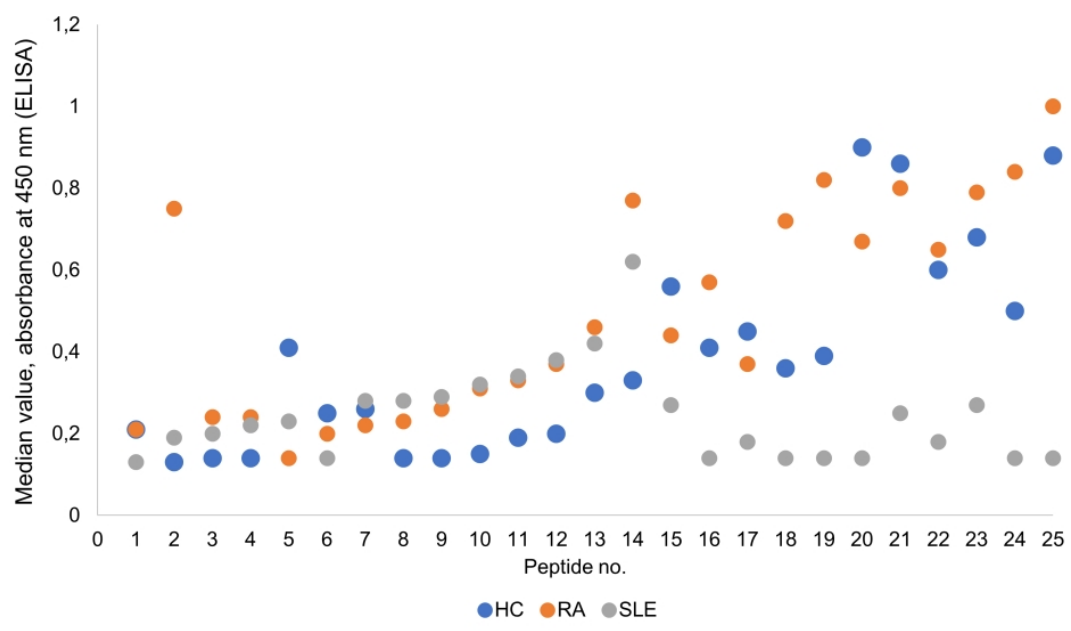

Figure 2C. Median values for absorbance obtained by ELISA, PEP1-PEP25. HC = healthy control, RA = rheumatoid arthritis; SLE = systemic lupus erythematosus.

$338 \times 190 \mathrm{~mm}(300 \times 300 \mathrm{DPI})$ 


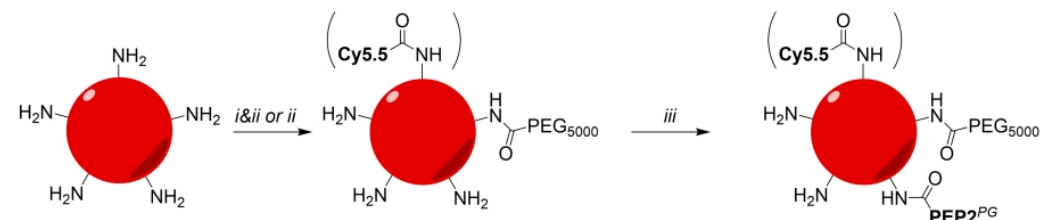

PAMAM G5 (1)

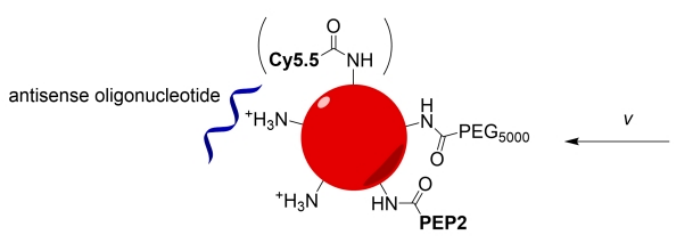

NP1, NP2 (containg Cy5.5) NP1.1, NP2.1 (no Cy5.5)

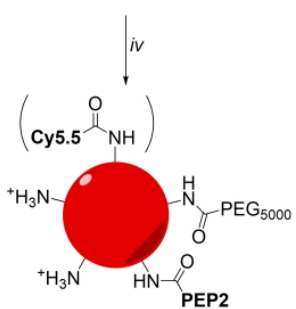

Figure 3A. Synthesis and characterization of nanoparticles modified with epitope PEP2, derived from PAMAM. Reaction conditions: i. Sulfo-Cy5.5 NHS, 100 mM bicarbonate buffer, pH 8.3, room temperature, overnight; ii. mPEG-COOH $5 \mathrm{kDa}$; NHS/EDC; $100 \mathrm{mM}$ bicarbonate buffer:DMF 4:1, v/v, pH 8.3, room temperature, overnight; iii. PEP2, DMSO:MQ water $1: 1 \mathrm{v} / \mathrm{v}, \mathrm{HOBt} / \mathrm{EDC}, 2 \mathrm{~h}$; iv. TFA $88 \%$, H2O $5 \%$, phenol $5 \%$, TIPS 2 $\%, 8 \mathrm{~h}$, room temperature; v. ASO, MQ water, room temperature, $4 \mathrm{~h}$.

$338 \times 190 \mathrm{~mm}(300 \times 300 \mathrm{DPI})$ 
Step 1.
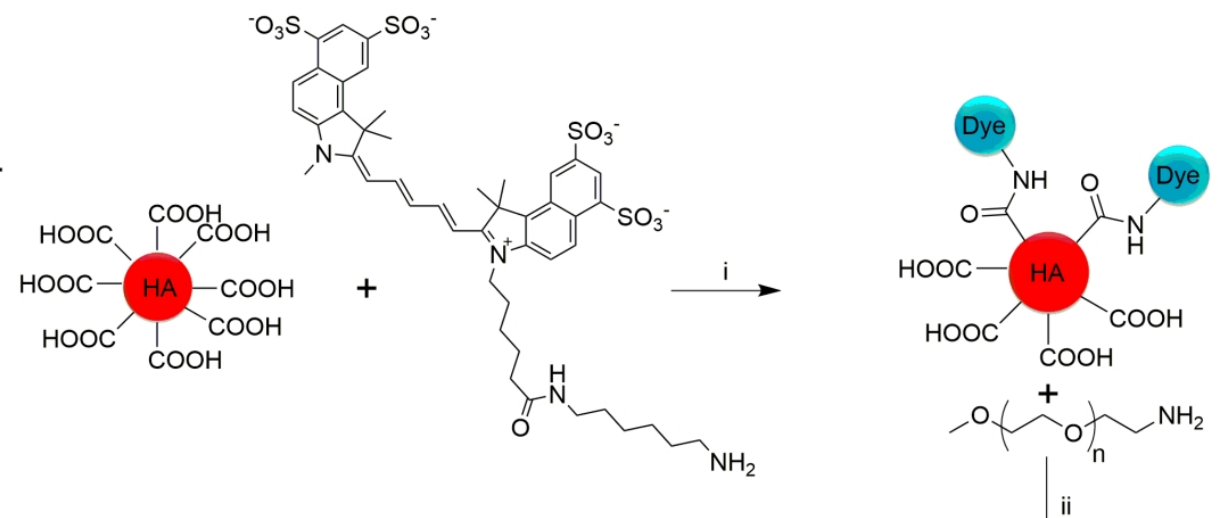

Step 2
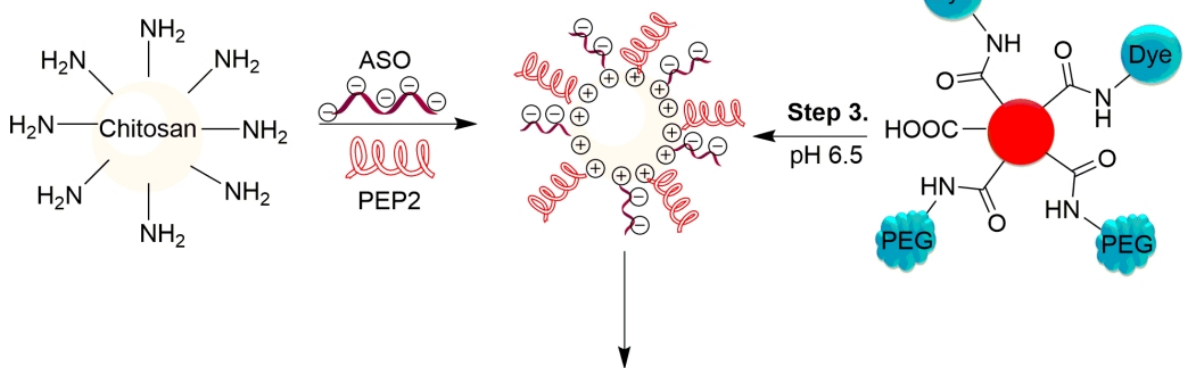

NP4

Figure 3B. Synthesis and characterization of nanoparticles modified with epitope PEP2, derived chitosanhyaluronic acid. Reaction conditions: Step 1. i. Sulfo-Cy5.5 amine, $100 \mathrm{mM}$ bicarbonate buffer, pH 8.3, room temperature, 1000 rpm, 6 h; ii. mPEG-amine 5 kDa; NHS/EDC; 100 mM bicarbonate buffer, pH 8.3, room temperature, overnight. Step 2. Chitosan, ASO, PEP2, MQ water, pH 6.5, $1000 \mathrm{rpm}$, room temperature, 30 min. Step 3. Product of step 1, product of step 2, MQ water, pH 6.5, room temperature, 30 min.

$184 \times 178 \mathrm{~mm}(300 \times 300 \mathrm{DPI})$ 


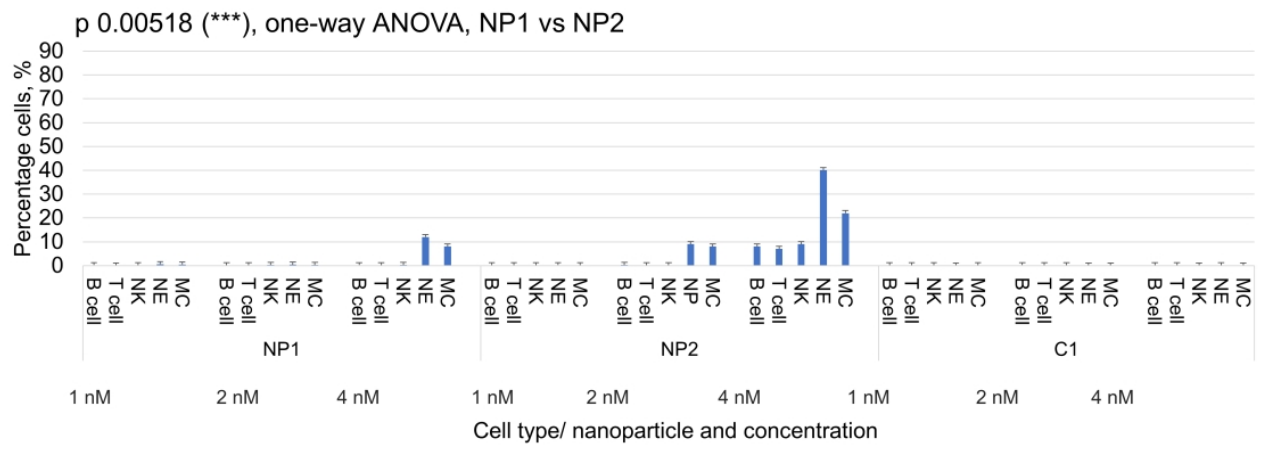

Figure 4. Nanoparticle recognition by neutrophil and monocyte population, studied by flow cytometry. Human blood was incubated with nanoparticles at designated concentration followed by flow cytometry staining and analysis. Frequency of nanoparticle-associated cells is shown $(A, B)$; Statistical analysis was done using one-way ANOVA in R. ** 95\% significance; *** $99 \%$ significance. 


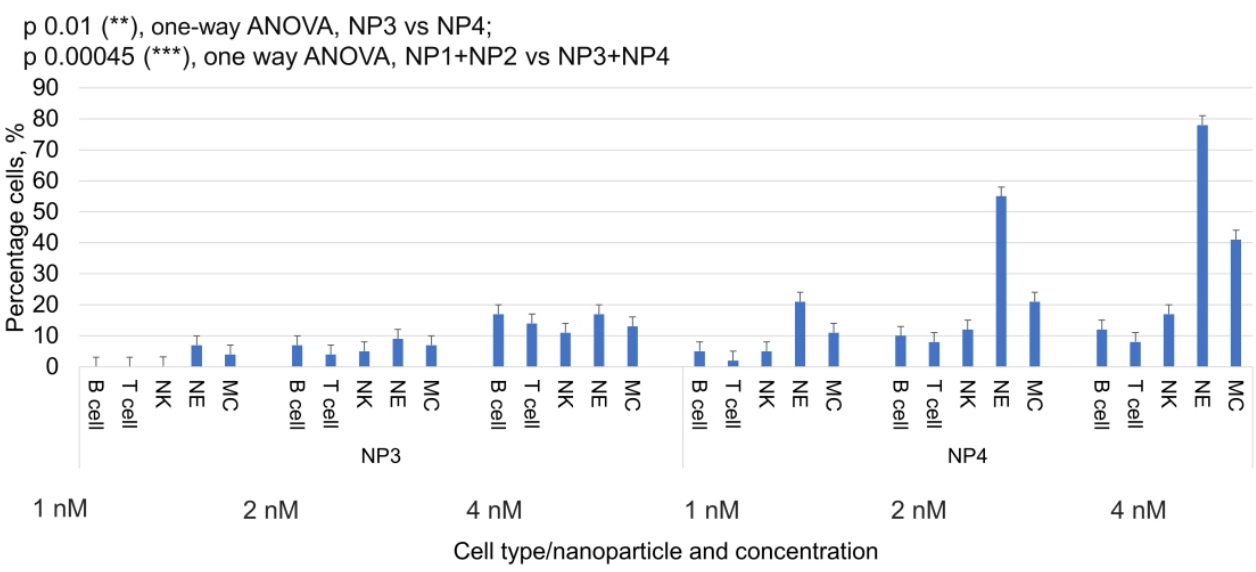

Figure 4. Nanoparticle recognition by neutrophil and monocyte population, studied by flow cytometry. Human blood was incubated with nanoparticles at designated concentration followed by flow cytometry staining and analysis. Frequency of nanoparticle-associated cells is shown (A,B); Statistical analysis was done using one-way ANOVA in R. ** $95 \%$ significance; $* * * 99 \%$ significance. 
1

2

3

4

5

6

7

8

9

10

11

12

13

14

15

16

17

18

19

20

21

22

23

24

25

26

27

28

29

30

31

32

33

34

35

36

37

38

39

40

41

42

43

44

45

46

47

48

49

50

51

52

53

54

55

56

57

58

59

60

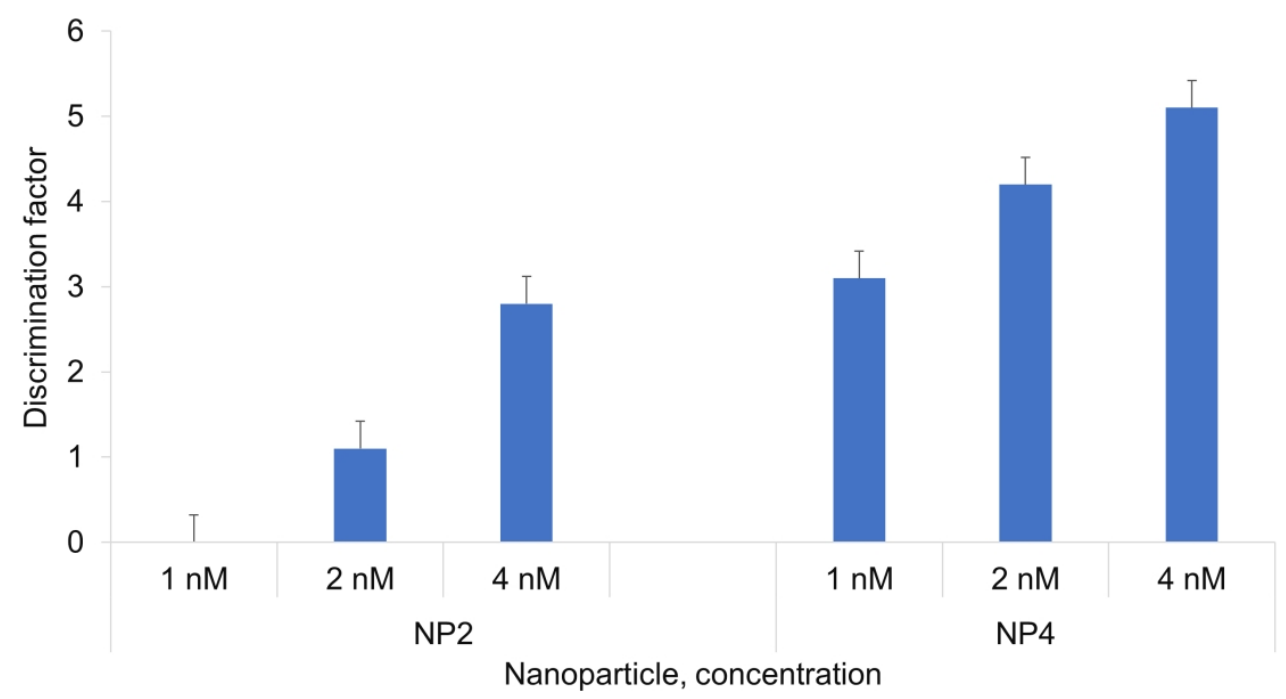

Figure 4C. Discrimination of neutrophils (NE) by nanoparticles NP2 and NP4, calculated as the ratio of frequency of nanoparticle+neutrophil to frequency of nanoparticle+monocytes, B, T and NK cells. Statistical analysis was done using one-way ANOVA in R. ** $95 \%$ significance; $* * * 99 \%$ significance. 

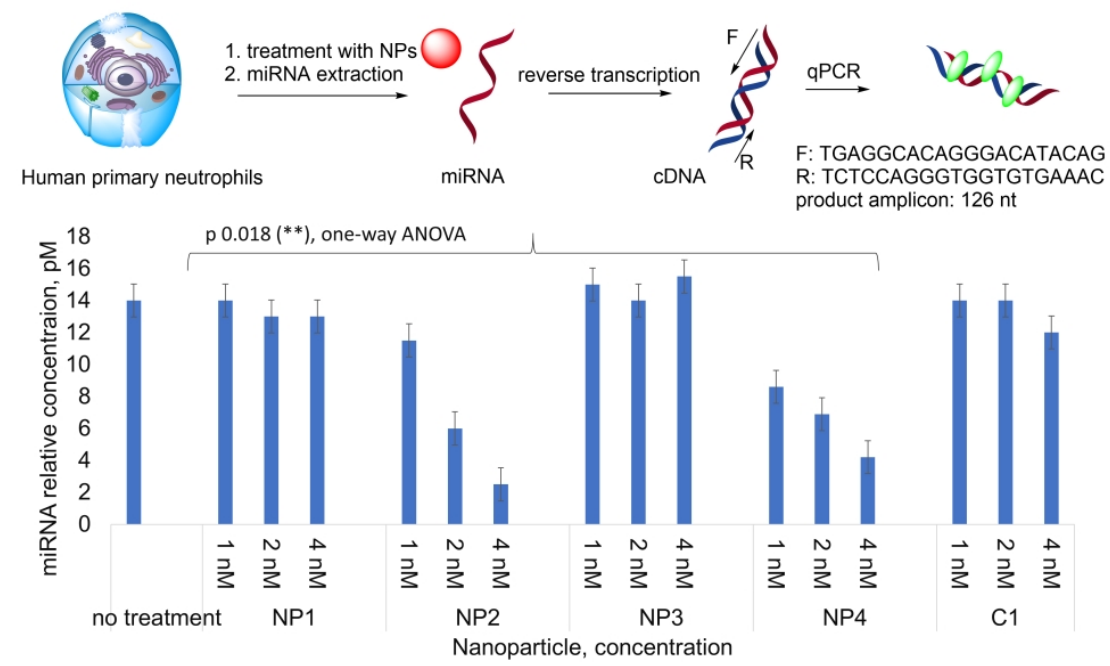

Figure 5. RT PCR of miR-125b-5p in primary human neutrophils. F, R = forward, reverse primer. $338 \times 190 \mathrm{~mm}(300 \times 300 \mathrm{DPI})$ 


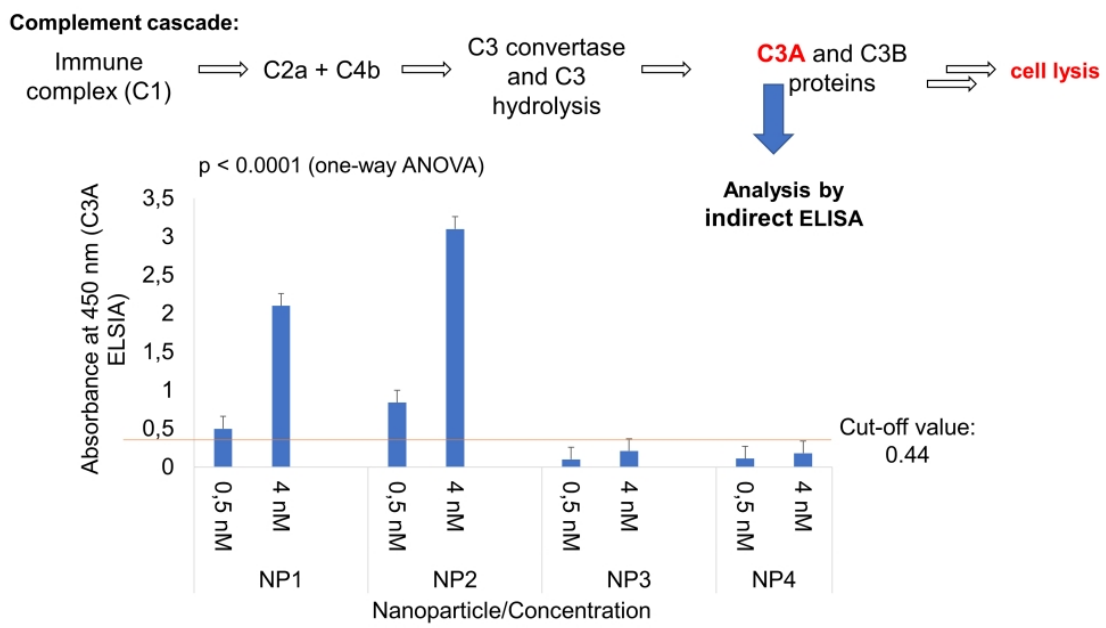

Figure 6A. Complement activation test. General scheme of complement cascade showing key proteins and C3A generation, and results for C3A levels measured by indirect ELISA. Incubation of NP1-NP4 with human blood were conducted in $0.5 \mathrm{nM}$ and $4 \mathrm{nM}$ concentrations.

$338 \times 190 \mathrm{~mm}(300 \times 300 \mathrm{DPI})$ 


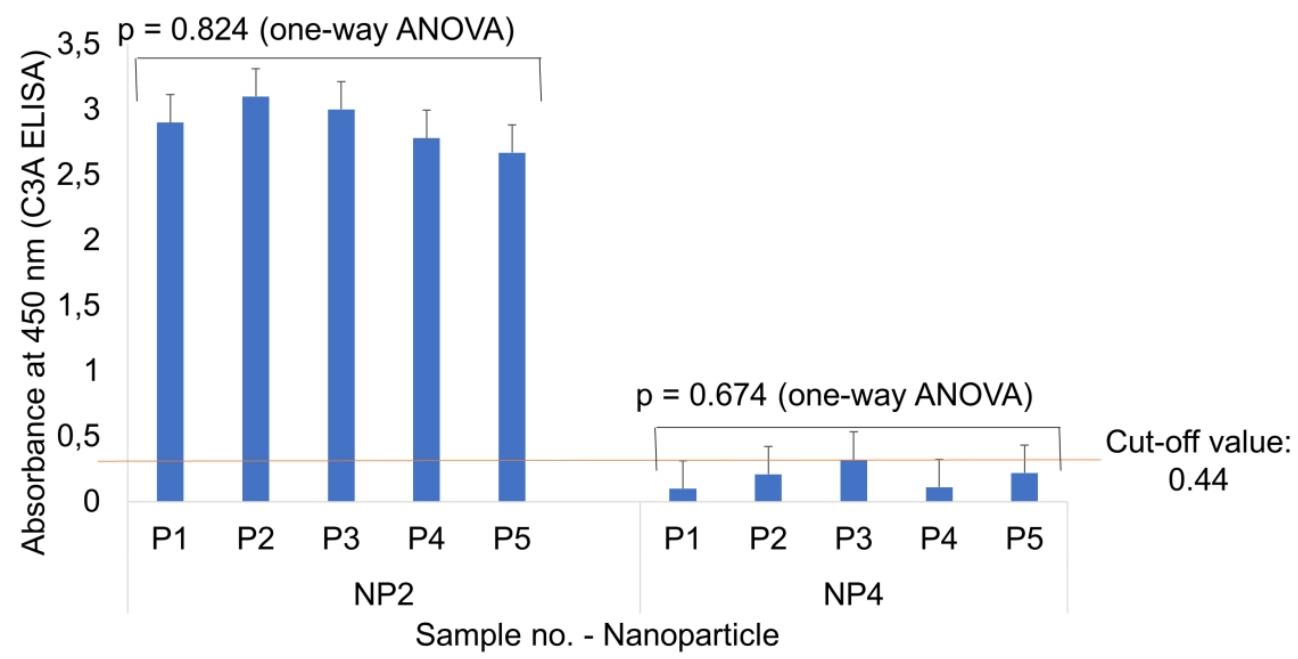

Figure 6B. Complement activation test. Patient variation study for five blood donors, $4 \mathrm{nM}$ concentration of NP2 and NP4. Cut-off value for negative control and 1:1500 blood dilution has been 0.44 . 


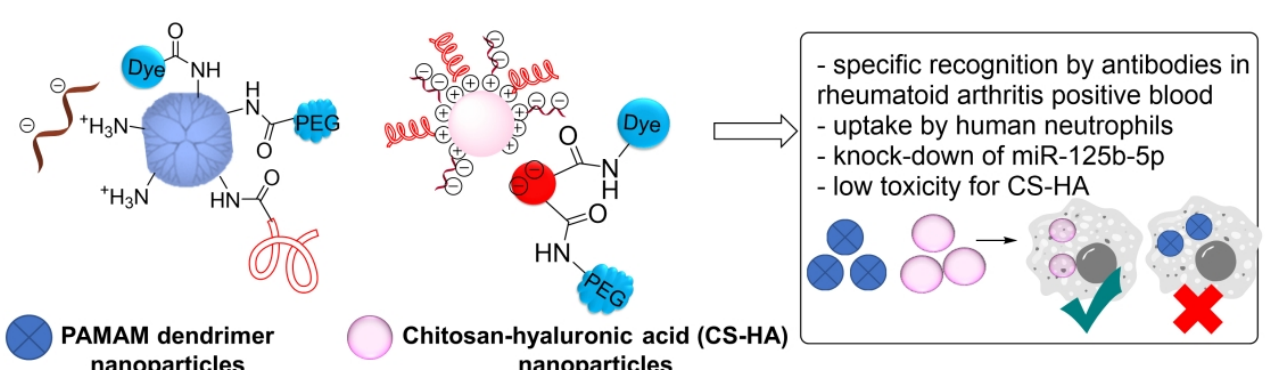

Graphical abstract 